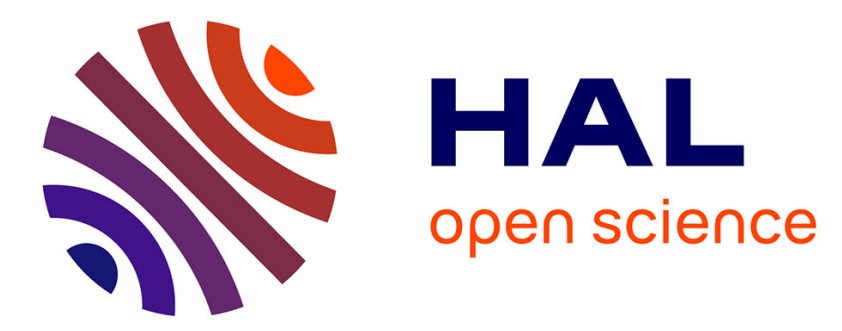

\title{
Investigation of polycarbazoles thin films prepared by electrochemical oxidation of 3- and 9-substituted carbazoles
}

\author{
Emmanuel Contal, Sophie Lakard, Frédéric Dumur, Boris Lakard
}

\section{To cite this version:}

Emmanuel Contal, Sophie Lakard, Frédéric Dumur, Boris Lakard. Investigation of polycarbazoles thin films prepared by electrochemical oxidation of 3- and 9-substituted carbazoles. Progress in Organic Coatings, 2022, 162, pp.106563. 10.1016/j.porgcoat.2021.106563 . hal-03396114

HAL Id: hal-03396114

https://hal.science/hal-03396114

Submitted on 22 Oct 2021

HAL is a multi-disciplinary open access archive for the deposit and dissemination of scientific research documents, whether they are published or not. The documents may come from teaching and research institutions in France or abroad, or from public or private research centers.
L'archive ouverte pluridisciplinaire HAL, est destinée au dépôt et à la diffusion de documents scientifiques de niveau recherche, publiés ou non, émanant des établissements d'enseignement et de recherche français ou étrangers, des laboratoires publics ou privés. 


\title{
Investigation of polycarbazoles thin films prepared by electrochemical
}

\section{oxidation of 3- and 9- substituted carbazoles}

\author{
Emmanuel Contal ${ }^{1}$, Sophie Lakard ${ }^{1}$, Frédéric Dumur $^{2}$, Boris Lakard $^{1, *}$
}

1 Univ. Bourgogne Franche-Comté, Institut UTINAM, UMR CNRS 6213, F-25030,

Besançon, France

2 Aix-Marseille University, Institut de Chimie Radicalaire UMR CNRS 7273, F-13397

Marseille, France

* boris.lakard@univ-fcomte.fr

\begin{abstract}
Conducting polymers such as polycarbazole and its derivatives have attracted much attention due to their remarkable electrical and optical properties. To prepare polycarbazole derivatives, a variety of substituents can be added to the nitrogen atom of the carbazole monomers or to their 3- and 6- positions. In the present study, carbazole monomers bearing hydrogen, methyl or benzyl group at the $N$-position and styryl or (naphthalen-1- or -2-yl)vinyl substituents at the 3-position were synthesized. Then, the electro-oxidation of the different carbazole derivatives was carried out in acetonitrile with potentiodynamic and potentiostatic electrochemical methods. Although all monomers were successfully electrochemically oxidized, leading to the formation of polymer films on the working electrode surface, the electrochemical behavior, electrochromic properties, morphology, thickness, and roughness of the films varied greatly depending on the nature of the substituents. Among all the polycarbazole films obtained, those prepared from monomers unsubstituted at 9-position
\end{abstract}


appeared to be the most promising due to their high electroactivity, electrochromism, good adhesion to the substrate and homogeneous structure.

Keywords: Conducting polymers; Electrochemistry; Carbazoles; Reactivity; Thin solid films.

\section{Introduction}

For a long time, polymers were considered as electrically insulating materials and most of their applications were based on their insulating properties. However, it all changed in 1977 when the semiconducting properties of doped polyacetylene were evidenced by Shirakawa and coworkers who quickly noticed that the conductivity of polyacetylene was dependent on the level of oxidation and can be tuned to cover the full range from insulators to metals [1]. Since this discovery, other conducting polymers (CPs) have been prepared, such as polyaniline [2], polypyrrole [3] or polythiophene [4], that received much attention in the field of material science due to their remarkable optical and electrical properties that result from their intrinsic chemical structure $[5,6]$. Indeed, CPs are conjugated molecules with extended $\pi$ electron delocalization along their polymer backbone due to alternating single and double bonds that allow charge carriers to move freely along the polymer structure. Electrochemical oxidation and chemical oxidation of a heterocyclic monomer are the two main methods of synthesizing a $\mathrm{CP}$ although other methods such as enzymatic catalyzed polymerization [7], vapor phase polymerization [8] and photochemical polymerization [9] are also sometimes used. Due to their numerous advantages such as their high and tunable electrical conductivity, mechanical flexibility, lightness, low-cost and ease to be synthesized, functionalized, nanostructured, or associated with other compounds to prepare composites, CPs have been used for many applications such as: energy storage in supercapacitors [10, 11] and batteries [12, 13], corrosion 
inhibition [14, 15], gas sensing [16, 17] and biosensing [18, 19], optoelectronics [20, 21], and biomedicine $[22,23]$.

$9 \mathrm{H}$-Carbazole is a heterocyclic compound consisting of two benzene rings fused on either side of a central five-membered ring. This fully aromatic character provides it a good chemical and environmental stability. A large variety of substituents can be added on the nitrogen atom to provide a much better solubility in common solvents, to protect the reactive secondary amine at the 9-position, and to tune its electrical and optical properties. But $9 H$-carbazole can also be substituted or polymerized either at the 3- and 6- positions or 2- and 7- positions to yield polycarbazole derivatives with good photoactive and electroactive properties due to their high hole transporting mobility and strong absorption in the UV region [24-27]. Due to these characteristics, polycarbazole derivatives are very interesting for applications such as light emitting diodes [28, 29], transistors [30], photovoltaic devices [31, 32], and (bio)sensors [3336]. Polycarbazoles can be obtained either by chemical polymerization of carbazole in the presence of an oxidizing agent, such as ferric chloride, as first evidenced by Branch and Tucker $[37,38]$, or by electrochemical polymerization leading to a thin film at the surface of a conducting electrode as first described by Ambrose and Nelson [39, 40]. The resulting films present numerous advantages such as homogeneity, controllable thickness, tunable conductivity, and ease of processing [41].

The electrochemical oxidation of $9 \mathrm{H}$-carbazole starts with the formation of the radical cation in a one-electron process. Then, the radical cation couples with either another radical cation or a parent molecule leading to dimers. This coupling is accompanied by the loss of two protons which are further reduced in the cathodic cycle [24]. The dimer has a lower oxidation potential than the monomer, and therefore the oxidation of the oligomers takes place leading to the growth of a polymer film at the electrode surface. Moreover, positions 3, 6, and 9 have been shown to be the most reactive $[39,40]$. 9-Substituted carbazoles are supposed to behave in a 
similar way to $9 H$-carbazole, and electro-oxidation of 9-substituted carbazoles by inert groups such as alkyl (methyl, ethyl, dimethyl) [39, 41, 42], phenyl [39, 43], and etheroxide groups [33] has been found to yield the first terms soluble oligomers linked at the 3,6-positions since the 9position is already occupied. Recently, our group also investigated the oxidation of carbazole substituted by -ethyl, -butyl, -hexyl, and -octyl groups at the 9-position in order to carry out the electrodeposition of polycarbazole derivatives [45]. Unfortunately, no polymerization was observed for either one of them due to the high stability of resulting radical cation dimers as evidenced by fast electrochemistry experiments. On the contrary, for other carbazole derivatives, obtained by chemical grafting of vinyl, acid, or ester groups on the 9-position of carbazole, radical cations were much less stable and polymerization process was more efficient leading to the formation of polymer films. The electrochemical oxidation of 3 -substituted carbazoles is generally similar to that of $9 H$-carbazole and leads to 6,6 '-bicarbazyls (main product) and 9-9'-bicarbazyls (minor product) while the electro-oxidation of 3-substituted-9alkyl carbazoles only gives 6,6'-bicarbazyls [24]. However, the ability to polymerize of 3substituted carbazoles depends on the nature of the substituents. Indeed, we have recently shown that the electro-oxidation of 3-ethycarbazole and 3-phenylcarbazole leads to the formation of solid polycarbazoles films while no polymerization occurs when 3-tertbutylcarbazole is electro-oxidized due to the higher stability of its radical cations [46].

The present work aims at synthesizing carbazole derivatives with different substituents at the 3- and 9-positions (Fig. 1), and then attempting to electropolymerize them to form polymer thin films on the surface of electrodes. The electrodeposition or not of polymers from these different monomers and the characteristics of the polymer films should allow us to improve our understanding of the reactivity of carbazoles. 


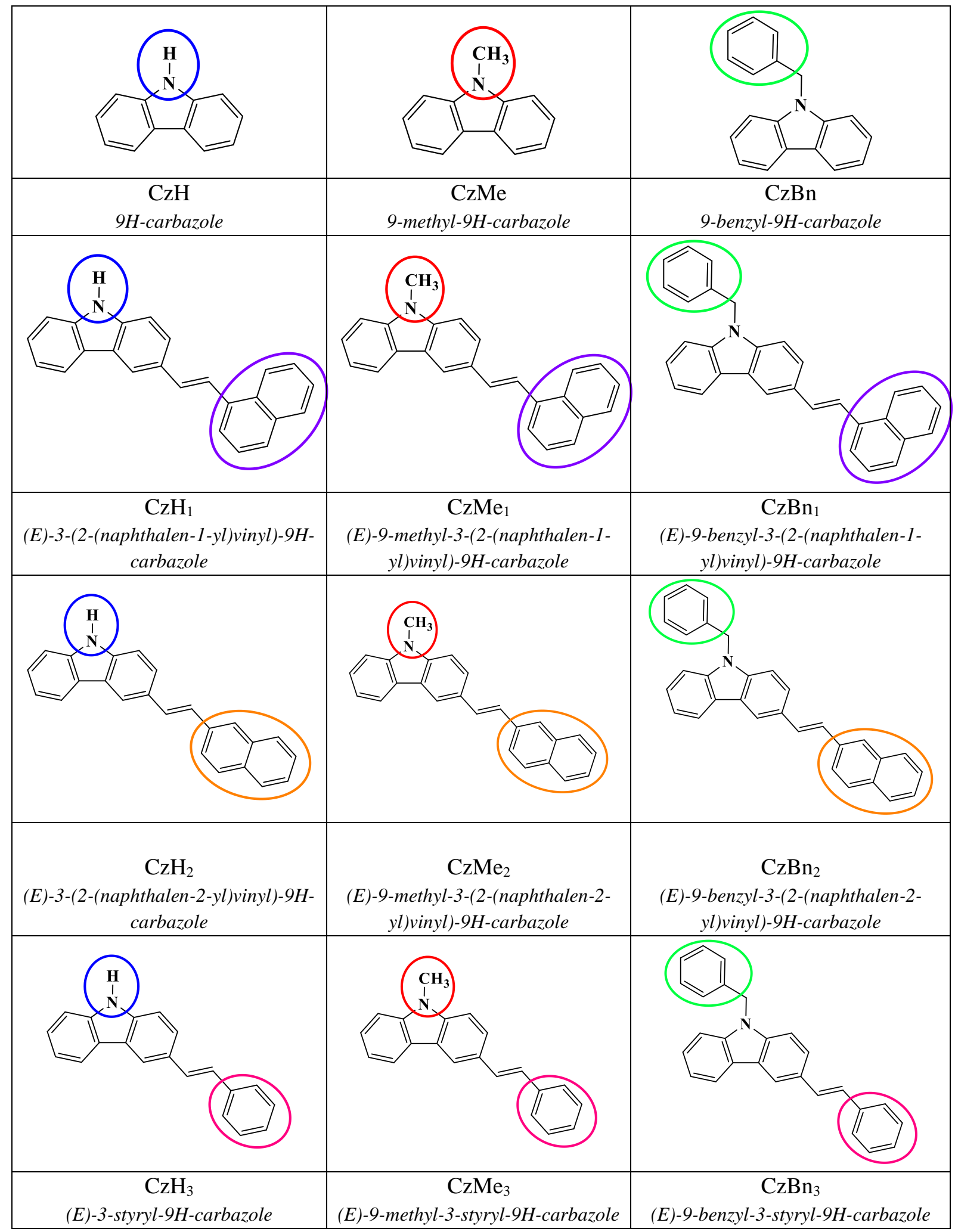

Figure 1. The different carbazole derivatives investigated in this study.

\section{Materials and methods}




\subsection{Reagents}

9H-Carbazole (Cz, 95\%) was purchased from Sigma Aldrich. 9-Methyl-9H-carbazole (CzMe, 99\%) and 9-benzyl-9H-carbazole (CzBn, 98\%) were from TCI America. Acetonitrile was purchased from Fisher Scientific and used as solvent for electrochemical experiments. Lithium perchlorate (95\%) was purchased from Sigma Aldrich and used as supporting salt for electrochemical experiments. All other reagents and solvents were purchased from Sigma Aldrich or Alfa Aesar and used as received without further purification. Mass spectroscopy was performed by the Spectropole of Aix-Marseille University. ESI mass spectral analyses were recorded with a 3200 QTRAP (Applied Biosystems SCIEX) mass spectrometer. The HRMS mass spectral analysis was performed with a QStar Elite (Applied Biosystems SCIEX) mass spectrometer. Elemental analyses were recorded with a Thermo Finnigan EA 1112 elemental analysis apparatus driven by the Eager 300 software. ${ }^{1} \mathrm{H}$ and ${ }^{13} \mathrm{C}$ NMR spectra were determined at room temperature in $5 \mathrm{~mm}$ o.d. tubes on a Bruker Avance 400 spectrometer of the Spectropole: ${ }^{1} \mathrm{H}(400 \mathrm{MHz})$ and ${ }^{13} \mathrm{C}(100 \mathrm{MHz})$. The ${ }^{1} \mathrm{H}$ chemical shifts were referenced to the solvent peak $\mathrm{CDCl}_{3}(7.26 \mathrm{ppm})$ and the ${ }^{13} \mathrm{C}$ chemical shifts were referenced to the solvent peak $\mathrm{CDCl}_{3}(77.0 \mathrm{ppm})$. (E)-9-Benzyl-3-(2-(naphthalen-1-yl)vinyl)-9H-carbazole $\left(\mathrm{CzBn}_{1}\right),(E)-9$ methyl-3-(2-(naphthalen-2-yl)vinyl)-9H-carbazole $\left(\mathrm{CzMe}_{2}\right),(E)-9-$ benzyl-3-(2-(naphthalen-2yl)vinyl)-9H-carbazole $\left(\mathrm{CzBn}_{2}\right),(E)$-3-styryl-9H-carbazole $\left(\mathrm{CzH}_{3}\right),(E)$-9-benzyl-3-styryl-9Hcarbazole $\left(\mathrm{CzBn}_{3}\right)$, 9H-carbazole-3-carbaldehyde, 9-methyl-9H-carbazole-3-carbaldehyde, 9benzyl-9H-carbazole-3-carbaldehyde, benzyltriphenyl-phosphonium bromide, (naphthalen-1ylmethyl)triphenylphosphonium chloride and (naphthalen-2-ylmethyl)triphenylphosphonium chloride were synthesized as previously reported in the literature, without modification and in similar yields [47].

General procedure: To a suspension of the appropriate carbazole-3-carbaldehyde (2.28 mmol, 1 eq.) and aryltriphenylphosphonium bromide (2.28 mmol, 1 eq.) in $100 \mathrm{~mL}$ dry THF was added 
sodium hydride $60 \%$ in oil $(1.67 \mathrm{~g}, 41.67 \mathrm{mmol}, \mathrm{M}=24 \mathrm{~g} / \mathrm{mol})$. The solution was refluxed overnight. The residue was quenched with water. The solution was extracted several times with DCM, the organic phases were combined, dried over magnesium sulfate and the solvent removed under reduced pressure. Addition of ethanol precipitated a white solid that was filtered off, washed with cold ethanol and dried under vacuum.

9-methyl-3-styryl-9H-carbazole ( $\left.\mathrm{CzMe}_{3}\right)$

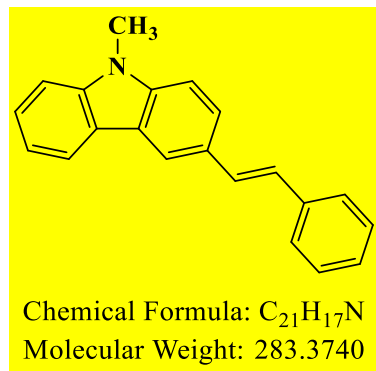

Starting from 9-methyl-9H-carbazole-3-carbaldehyde (0.48 g, $2.28 \mathrm{mmol}, \mathrm{M}=209.24 \mathrm{~g} / \mathrm{mol})$ and benzyltriphenylphosphonium bromide $(0.99 \mathrm{~g}, 2.28 \mathrm{mmol}, \mathrm{M}=433.32 \mathrm{~g} / \mathrm{mol}): 529 \mathrm{mg}$, $82 \%$ yield. ${ }^{1} \mathrm{H}$ NMR $\left(\mathrm{CDCl}_{3}\right) \delta 3.87(\mathrm{~s}, 3 \mathrm{H}), 7.16(\mathrm{~d}, 1 \mathrm{H}, J=16.3 \mathrm{~Hz}), 7.23-7.28(\mathrm{~m}, 1 \mathrm{H}), 7.33$ $(\mathrm{d}, 1 \mathrm{H}, J=16.3 \mathrm{~Hz}), 7.35-7.42(\mathrm{~m}, 4 \mathrm{H}), 7.50(\mathrm{td}, 1 \mathrm{H}, J=7.1 \mathrm{~Hz}, J=1.2 \mathrm{~Hz}), 7.57(\mathrm{~d}, 1 \mathrm{H}, J=$ $7.2 \mathrm{~Hz}), 7.69(\mathrm{dd}, 1 \mathrm{H}, J=8.5 \mathrm{~Hz}, J=1.6 \mathrm{~Hz}), 8.13(\mathrm{~d}, 1 \mathrm{H}, J=7.7 \mathrm{~Hz}), 8.24(\mathrm{~d}, 1 \mathrm{H}, J=1.6$ $\mathrm{Hz}) ;{ }^{13} \mathrm{C} \mathrm{NMR}\left(\mathrm{CDCl}_{3}\right) \delta 29.2,108.7,118.7,119.1,120.4,122.9,123.2,124.6,125.9,126.1$, 126.3, 127.1, 128.6, 128.7, 129.7, 138.0, 140.8, 141.5; HRMS (ESI MS) m/z: theor: 283.1361 found: $283.1364\left(\mathrm{M}^{+}\right.$detected); Anal. Calc. for $\mathrm{C}_{21} \mathrm{H}_{17} \mathrm{~N}$ : C, 89.0; H, 6.0; N, 4.9; Found: $\mathrm{C}$, 89.3; H, 5.7; N, $4.7 \% ; \mathrm{mp} 129-131^{\circ} \mathrm{C}$

\section{9-methyl-3-(1-(naphthalen-1-yl)vinyl)-9H-carbazole (CzMe 1$)$}

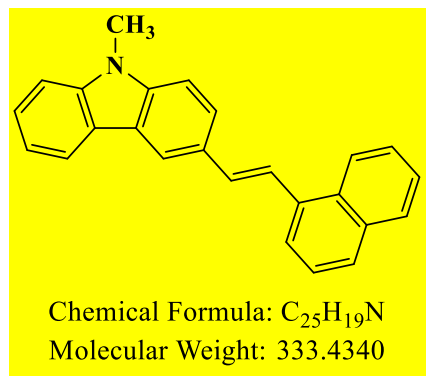


Starting from 9-methyl-9H-carbazole-3-carbaldehyde (0.48 g, $2.28 \mathrm{mmol}, \mathrm{M}=209.24 \mathrm{~g} / \mathrm{mol})$ and (naphthalen-1-ylmethyl)triphenylphosphonium chloride $(1 \mathrm{~g}, 2.28 \mathrm{mmol}, \mathrm{M}=438.93$ g/mol): $653 \mathrm{mg}, 86 \%$ yield. ${ }^{1} \mathrm{H}$ NMR $\left(\mathrm{CDCl}_{3}\right) \delta 3.89(\mathrm{~s}, 3 \mathrm{H}), 7.28(\mathrm{td}, 1 \mathrm{H}, J=7.9 \mathrm{~Hz}, J=0.9$ Hz), $7.37(\mathrm{~d}, 1 \mathrm{H}, J=16.0 \mathrm{~Hz}), 7.42-7.44(\mathrm{~m}, 2 \mathrm{H}), 7.49-7.59(\mathrm{~m}, 4 \mathrm{H}), 7.78-7.82(\mathrm{~m}, 3 \mathrm{H}), 7.89$ $(\mathrm{dd}, 1 \mathrm{H}, J=7.9 \mathrm{~Hz}, J=1.4 \mathrm{~Hz}), 7.93(\mathrm{~d}, 1 \mathrm{H}, J=16.0 \mathrm{~Hz}), 8.16(\mathrm{~d}, 1 \mathrm{H}, J=7.7 \mathrm{~Hz}), 8.32-8.34$ $(\mathrm{m}, 2 \mathrm{H}) ;{ }^{13} \mathrm{C} \mathrm{NMR}\left(\mathrm{CDCl}_{3}\right) \delta 29.2,108.6,108.8,118.8,119.2,120.4,122.9,123.1,123.2$, $123.3,124.0,124.7,125.7,125.8,125.9,127.5,128.6,129.0,131.5,132.7,133.8,135.6,140.9$, 141.5; HRMS (ESI MS) m/z: theor: 333.1517 found: $333.1512\left(\mathrm{M}^{+}\right.$. detected); Anal. Calc. for $\mathrm{C}_{25} \mathrm{H}_{19} \mathrm{~N}: \mathrm{C}, 90.1 ; \mathrm{H}, 5.7 ; \mathrm{N}, 4.2$; Found: $\mathrm{C}, 90.3 ; \mathrm{H}, 5.7 ; \mathrm{N}, 4.4 \% ; \mathrm{mp} 122-124^{\circ} \mathrm{C}$

\section{3-(2-(naphthalen-1-yl)vinyl)-9H-carbazole $\left(\mathrm{C}_{2} \mathrm{H}_{1}\right)$}

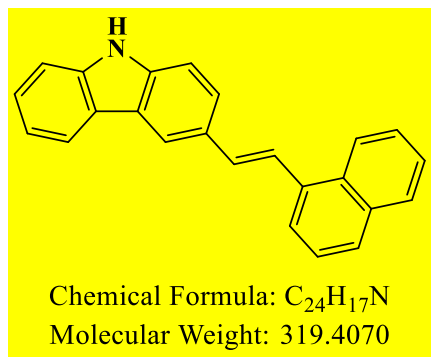

Starting from $9 H$-carbazole-3-carbaldehyde $(0.45 \mathrm{~g}, 2.28 \mathrm{mmol}, \mathrm{M}=195.22 \mathrm{~g} / \mathrm{mol})$ and (naphthalen-1-ylmethyl)triphenylphosphonium chloride (1 g, $2.28 \mathrm{mmol}, \mathrm{M}=438.93 \mathrm{~g} / \mathrm{mol})$ : $684 \mathrm{mg}, 94 \%$ yield. ${ }^{1} \mathrm{H}$ NMR $\left(\mathrm{CDCl}_{3}\right) \delta 7.39(\mathrm{td}, 2 \mathrm{H}, \mathrm{J}=7.8 \mathrm{~Hz}, \mathrm{~J}=0.8 \mathrm{~Hz}), 7.52-7.61(\mathrm{~m}$, 5H), $7.73(\mathrm{~d}, 1 \mathrm{H}, \mathrm{J}=14.0 \mathrm{~Hz}), 7.79-7.96(\mathrm{~m}, 6 \mathrm{H}), 8.15-8.21(\mathrm{~m}, 3 \mathrm{H}) ;{ }^{13} \mathrm{C} \mathrm{NMR}\left(\mathrm{CDCl}_{3}\right) \delta$ $110.6,117.1,120.5,121.0,123.5,124.0,124.2,125.4,125.9,126.1,126.3,126.5,127.9,128.7$, 131.3, 133.8, 133.9, 139.7; HRMS (ESI MS) m/z: theor: 319.1361 found: $319.1362\left(\mathrm{M}^{+}\right.$ detected); Anal. Calc. for $\mathrm{C}_{24} \mathrm{H}_{17} \mathrm{~N}$ : C, 90.2; H, 5.4; N, 4.4; Found: C, 90.3; H, 5.7; N, $4.3 \%$; $\operatorname{mp} 110-112^{\circ} \mathrm{C}$ 


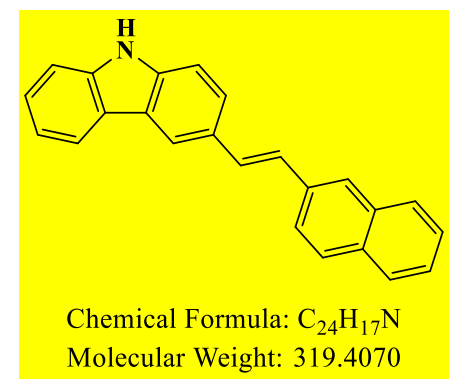

Starting from $9 H$-carbazole-3-carbaldehyde $(0.45 \mathrm{~g}, 2.28 \mathrm{mmol}, \mathrm{M}=195.22 \mathrm{~g} / \mathrm{mol})$ and (naphthalen-2-ylmethyl)triphenylphosphonium chloride (1 g, $2.28 \mathrm{mmol}, \mathrm{M}=438.93 \mathrm{~g} / \mathrm{mol})$ : $640 \mathrm{mg}, 88 \%$ yield. ${ }^{1} \mathrm{H}$ NMR $\left(\mathrm{CDCl}_{3}\right)$ $\delta 7.31-7.37$ (m, 2H), 7.41-7.55 (m, 4H), 7.73-7.90 (m, 8H), 8.10-8.16 (m, 2H); ${ }^{13} \mathrm{C} \mathrm{NMR}\left(\mathrm{CDCl}_{3}\right) \delta 110.6,119.6,120.3,120.8,123.2,123.5,124.1$, $125.2,125.7,126.3,126.5,127.7,127.8,128.5,132.7,133.7,133.8,139.5$; HRMS (ESI MS) m/z: theor: 319.1361 found: 319.1367 ( $\mathrm{M}^{+}$detected); Anal. Calc. for $\mathrm{C}_{24} \mathrm{H}_{17} \mathrm{~N}: \mathrm{C}, 90.2 ; \mathrm{H}, 5.4$;

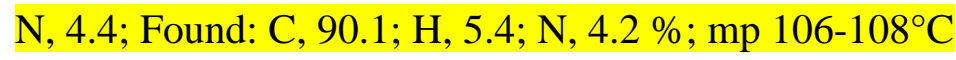

\subsection{Synthesis}

To carry out the substitution at the 9-position of the carbazole moiety, it is first necessary to deprotonate the nitrogen atom with a base, thus generating a negative charge on the nitrogen atom. Then, an alkyl halide $\left(\mathrm{R}_{1} \mathrm{X}\right)$ could be used as a functionalizing agent, generating the $\mathrm{N}$ $\mathrm{R}_{1}$ bond (Fig. 2). To introduce the formyl group at the 3- position of carbazole, a VilsmeierHaack reaction was used, enabling to prepare the different aldehyde in moderate to high yields. Then, by reacting the different aldehyde with the appropriate phosphonium salts $\left(\mathrm{R}_{2} \mathrm{CH}_{2}-\right.$ $\left.\mathrm{PPh}_{3}{ }^{+} \mathrm{X}^{-}\right)$in the presence of a strong base (e.g. $\mathrm{NaH}$ ), the Wittig reaction could furnish the different targeted compounds. It has to be noticed that for all reaction, a large excess of base was used to favor the reaction. This excess was notably justified when $9 H$-carbazole-3carbaldehyde was used as the aldehyde, a deprotonation reaction also occurring at the $\mathrm{NH}$ position of the carbazole moiety. All compounds $\mathrm{CzMe}_{1}, \mathrm{CzMe}_{3}, \mathrm{CzH}_{1}$ and $\mathrm{CzH}_{2}$ could be obtained in high yields, ranging from $82 \%$ for $\mathrm{CzMe}_{1}$ to $94 \%$ for $\mathrm{CzH}_{1}$. It has to be noticed that 
due to the polyaromatic nature of the different carbazole-based compounds, all products could be obtained in pure form simply by precipitation in ethanol, subsequent to hydrolysis with water and removal of the reaction solvent (THF).

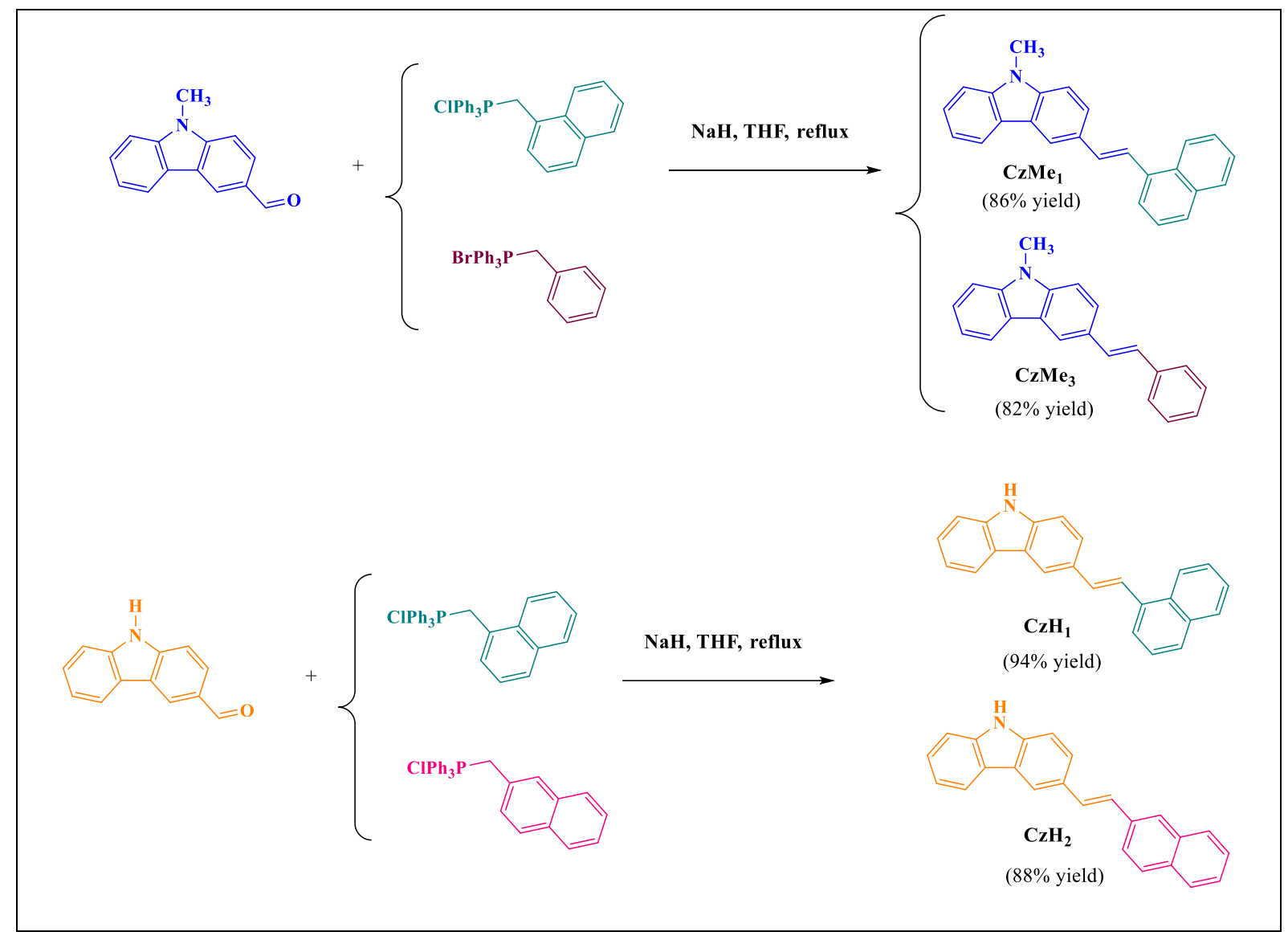

Figure 2. Synthetic routes to $\mathrm{CzMe}_{1}, \mathrm{CzMe}_{3}, \mathrm{CzH}_{1}$ and $\mathrm{CzH}_{2}$.

\subsection{Electrochemistry}

All electrochemical experiments were carried out at room temperature, using a VersaSTAT MC potentiostat/galvanostat from Princeton Applied Research, in a single-compartment cell with a three-electrode setup. This setup used a Saturated Calomel Electrode (SCE) as the reference electrode, a platinum sheet as the counter-electrode, and a platinum wire or FTO substrate as the working electrode. The electrolytic solution was composed of acetonitrile, lithium perchlorate $(0.1 \mathrm{~mol} / \mathrm{L})$ and one of the carbazole monomers previously described $(0.01 \mathrm{~mol} / \mathrm{L})$. 
The electrochemical oxidation of the different carbazole monomers was carried out at a platinum wire (area: $0.785 \mathrm{~mm}^{2}$ ) using cyclic voltammetry technique (5 potential scans were done at $50 \mathrm{mV} / \mathrm{s}$ ). Chronoamperometry technique was also used to perform the electrooxidation of the carbazole monomers (a potential of $+1.5 \mathrm{~V} / \mathrm{SCE}$ was applied during $3 \mathrm{~min}$ ) at a rectangular Fluorine doped Tin Oxide (FTO) substrates $(\mathrm{R}=80 \mathrm{~V} / \mathrm{square}$, dimensions: $3 \mathrm{~cm}$ $\mathrm{x} 1.5 \mathrm{~cm})$. The working electrode was rinsed with acetonitrile after electrodeposition of a polymer film. Then, the electroactivity of the resulting polymer films was estimated by performing a cyclic voltammetry at a Pt electrode coated with a polymer film in an electrolytic solution containing acetonitrile and lithium perchlorate $(0.1 \mathrm{~mol} / \mathrm{L})$ but no monomer.

\subsection{Characterization}

\section{- SEM microscopy}

The surface morphology of the polymer films was observed with a high-resolution Thermo Scientific Apreo 2 Scanning Electron Microscope with an electron beam energy of $5 \mathrm{keV}$ and a working distance of $10 \mathrm{~mm}$. No metallization pre-treatment was needed since the samples were conductive.

\section{- Profilometry}

The thickness and roughness of the polymer films were measured using a Dektak 150 surface profiler. Both thickness and roughness were obtained by moving this stylus perpendicular to the film over a scan length of $3000 \mu \mathrm{m}$ at a scan speed of $50 \mu \mathrm{m} / \mathrm{s} .5$ measurements were achieved at different positions for each film.

\section{- UV/Visible absorption spectroscopy}

Absorption spectra of the monomer solutions and polymer films obtained by electro-oxidation were performed using a SECOMAN UviLine 9400C spectrophotometer scanning a wavelength range from 190 to $1100 \mathrm{~nm}$. 


\section{Results and discussion}

3.1.Electrochemical oxidation of 9H-carbazole, 9-methyl-9H-carbazole and 9-benzyl-9Hcarbazole

Electrochemical oxidation of $9 \mathrm{H}$-carbazole is carried out by cyclic voltammetry $(\mathrm{CV})$ at a Pt electrode (Fig. 3a). During the first scan, an anodic peak, due to the oxidation of $9 \mathrm{H}$ carbazole monomers into radical cations, appears at $+1.06 \mathrm{~V} / \mathrm{SCE}$. After the first scan, the oxidation potential peak intensity increases, and the peak potential shifts slightly towards higher values. The gradual increase of the oxidation peak intensity with repeated scans indicates the progressive deposition of an adherent green film of conducting polycarbazole film (polyCz) on the Pt surface. The redox process of polycarbazole is also observed since a polyCz oxidation peak and a polyCz reduction peak are distinguishable at +0.75 and $+0.65 \mathrm{~V} / \mathrm{SCE}$, respectively. This electrochemical behavior is consistent with the electropolymerization mechanism of other aromatic heterocyclic compounds such as thiophene or pyrrole that has been reviewed by Sadki et al. [48].

It is well-known that some conducting polymer films possess a high electrochemical activity which means that it can easily switch between doped and dedoped forms, by exchange of anions between the film and the electrolyte, by varying the potential applied to the substrate [49]. To investigate the electroactivity of polyCz films, the electrode with the polymer film attached was removed from the growth electrolytic solution and placed in a monomer-free solution of acetonitrile+$+\mathrm{LiClO}_{4}$ for post-polymerization voltammetric analysis. The resulting postpolymerization $\mathrm{CV}$ exhibits an oxidation peak at $+1.4 \mathrm{~V} / \mathrm{SCE}$ and a reduction peak at +0.3 V/SCE (Fig. 3b). Moreover, the ratio of oxidation to reduction intensities $(\approx 1.7)$ is higher than unity, indicating that a higher amount of polymer is involved in the oxidation process than in the reduction process. In addition, the potential of the polyCz oxidation peak increases with 
successive cycles when its intensity decreases with successive cycles. These two phenomena indicate that the doping of the polyCz films by the perchlorate anions becomes more and more difficult with successive cycles. Similar trends are observed during the dedoping of the films since the potential of polyCz reduction peak becomes increasingly negative and its intensity decreases with successive cycles. It was also observed that the polycarbazole film is electrochromic. Indeed, during cyclic voltammetry experiments it turns green during the oxidation phase, and then becomes colorless during the reduction phase, and this during all successive cycles.

The 9-methyl-9H-carbazole and 9-benzyl-9H-carbazole monomers show very similar electrochemical behavior, but very different from the $9 H$-carbazole monomer. Indeed, both substituted carbazoles exhibit an oxidation peak between +1.0 and $+1.1 \mathrm{~V} / \mathrm{SCE}$, corresponding to the oxidation of monomers into radical cations (Fig. 3c-3e). But, after the first scan, the oxidation potential peak intensity does not increase, and the oxidation peak potential does not shift. In addition, the intensity of the oxidation peak is much higher for $9 H$-carbazole $(152 \mu \mathrm{A})$ than for the substituted carbazoles $(45 \mu \mathrm{A})$. This indicates that the resulting polymer films may be less conductive than polyCz. In addition, these polycarbazole derivatives are not very electroactive as evidenced by the low intensity of the oxidation and reduction peaks (Fig. 3d3e). Furthermore, in contrast to what was observed with the unsubstituted polycarbazole film, no electrochromism was observed for the films obtained from 9-methyl-9H-carbazole and 9benzyl-9H-carbazole.

It can also be noticed that in the case of 9-methyl-9H-carbazole, an adherent green film of conductive polycarbazole film appears on the Pt surface (Fig. 3c). On the contrary, in the case of 9-benzyl-9H-carbazole, no coating is visible on the Pt electrode at the end of the experiment (Fig. 3e), but the solution is green. In fact, the oxidation of this monomer leads to the formation of polymer on the working electrode, but the polymer does not adhere to the FTO substrate and 
falls into the solution. The difference in adhesion between substituted and unsubstituted monomers could be due to the degree of polymerization of the polymers since it has already been shown that the adhesive behavior of poly(3-alkylthiophenes) strongly vary with the length of the substituted chains and with the degree of polymerization [50].

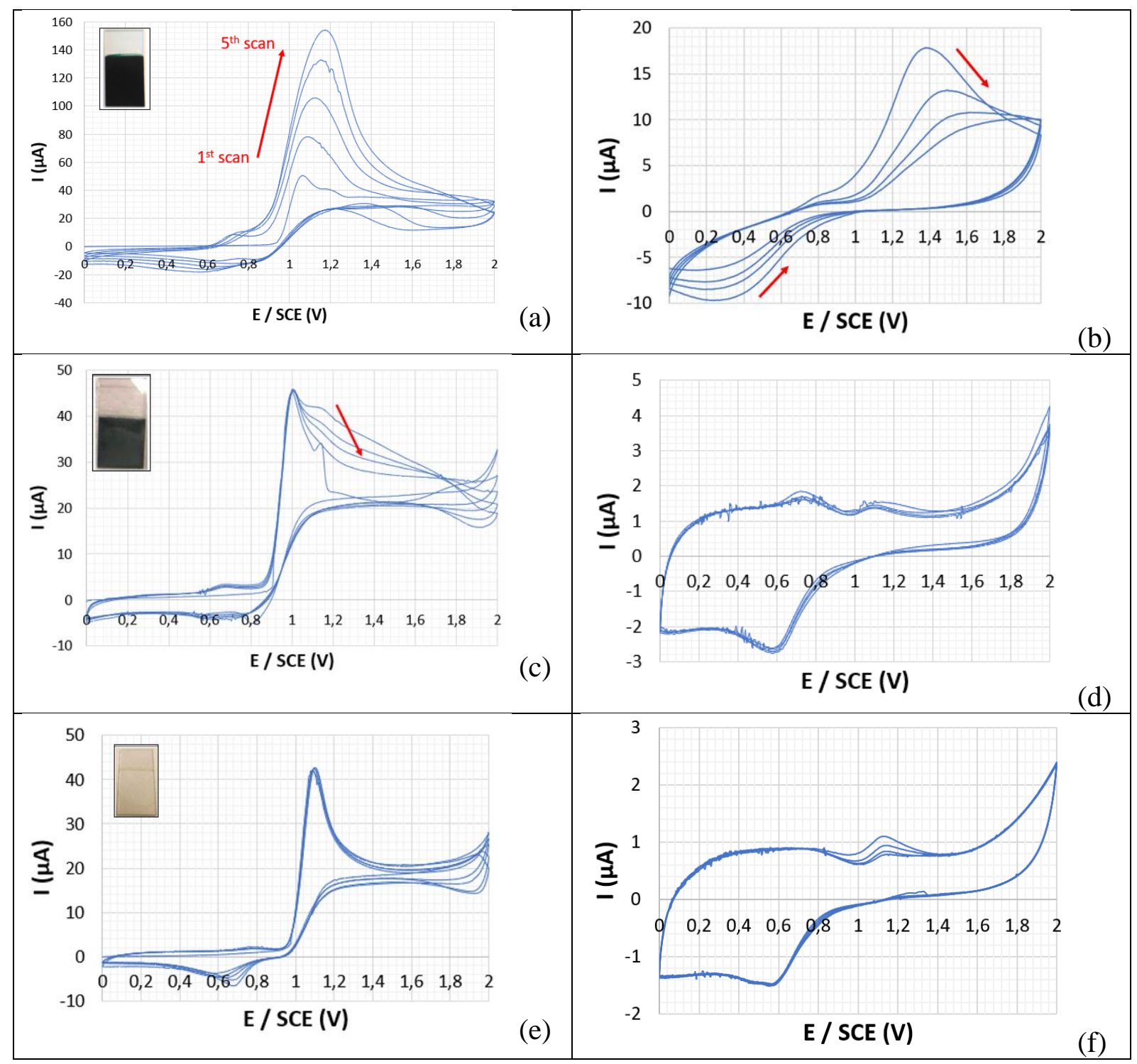

Figure 3. Electrochemical oxidation of carbazole derivatives $(0.01 \mathrm{M})$ in acetonitrile $+0.1 \mathrm{M}$ $\mathrm{LiClO}_{4}$ : (a) $\mathrm{Cz}$, (b) $\mathrm{CzMe}$, (c) $\mathrm{CzBn}$. Post-polymerization cyclic voltammetry of the resulting films in acetonitrile $+0.1 \mathrm{M} \mathrm{LiClO}_{4}$ : (d) $\mathrm{Cz}$, (e) $\mathrm{CzMe}$, (f) $\mathrm{CzBn}$.

The electrodeposited films were then characterized using electrochemistry, UV/Visible absorption spectroscopy, SEM microscopy and profilometry. The film obtained from $9 \mathrm{H}$ - 
carbazole presents globules randomly distributed on the surface of the working electrode (Fig. 4a), it also contains some cracks due to its high stiffness as previously demonstrated using AFM measurements of the Young's modulus of polycarbazole [51]. Besides, the comparison of the UV/visible absorption spectra of the monomer solution and the polymer film evidence that the absorption peak is shifted towards higher wavelenghts and has a much larger width which is consistent with the formation of a film composed of oligomers of different sizes with strong electronic conjugation (Fig. 5). Indeed, the monomer presents two sharp peaks at $230 \mathrm{~nm}$ and $290 \mathrm{~nm}$ when the polymer exhibits two wide peaks whose maximum are located at 350 and 690 $\mathrm{nm}$ (this absorption wavelength of the polymer corresponds to the red color whose complementary color is the green color observed for the coating). The average thickness of this film is $2.0 \mu \mathrm{m}$ and its average roughness is $0.1 \mu \mathrm{m}$ which is low for such electrodeposited polymer film. The morphology of the film obtained from 9-methyl-9H-carbazole is more original with the presence of feather duster-like structures spread over the electrode surface (Fig. 8a). Its average thickness and roughness were estimated to $6 \mu \mathrm{m}$ and $3 \mu \mathrm{m}$, respectively, indicating that the film is rougher than the polycarbazole film. The very thin film $(0.3 \mu \mathrm{m}$ thick according to profilometric measurements) obtained by oxidation of 9-benzyl- $9 H$-carbazole was also studied, but due to the desorption of most of the film during the electrochemical experiments, the SEM picture obtained is not meaningful (Fig. 10a). On the contrary, it is interesting to note that chronoamperometric experiments confirm that 9-benzyl- $9 \mathrm{H}$-carbazole is oxidized even if the corresponding monomer does not adhere to the electrode surface. Indeed, the electric charge density that circulated during the electrochemical oxidation of the different monomers was 1395, 1301 and $916{\mathrm{C} . \mathrm{cm}^{-2}}^{2}$ for $9 H$-carbazole, 9-methyl-9H-carbazole, and 9benzyl-9H-carbazole, respectively. Thus, the electric charge is slightly lower but not negligible at all in the case of 9-benzyl-9H-carbazole. 
In conclusion, the polymer film obtained by oxidation of $9 H$-carbazole is the most interesting one since it is conductive, electrochromic, thick, and smooth. Only the presence of cracks seems detrimental. In the next section, we will study three derivatives of $9 H$-carbazole obtained by substitution of the hydrogen atom located at 3-position by styryl and naphthalenyl, groups, and we will determine the influence of this substitution on the properties of the electrodeposited films.

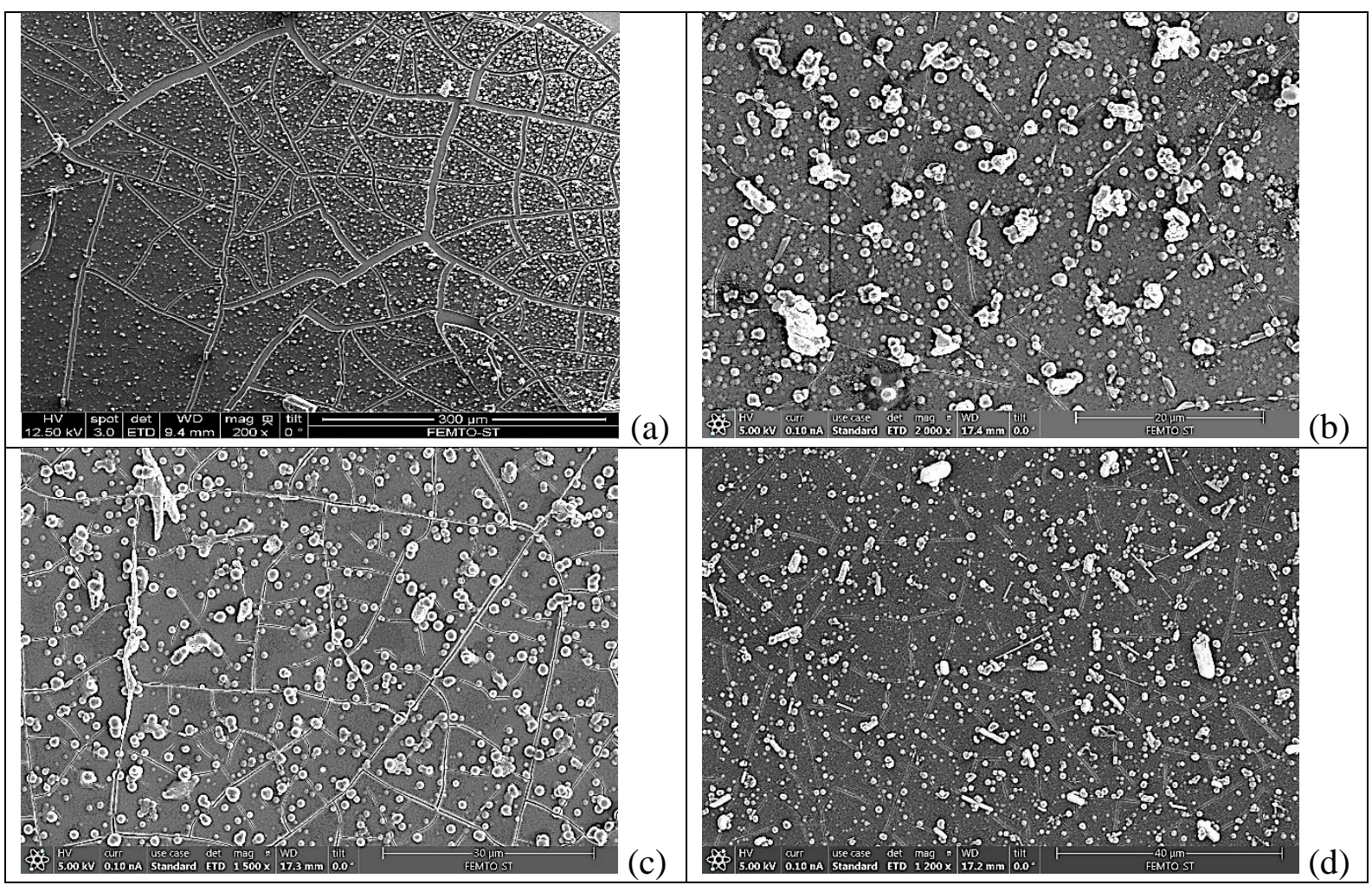

Figure 4. SEM images of the films obtained by oxidation of: $\mathrm{Cz}$ (a), $\mathrm{CzH}_{1}$ (b), $\mathrm{CzH}_{2}$ (c) and $\mathrm{CzH}_{3}(\mathrm{~d})$.

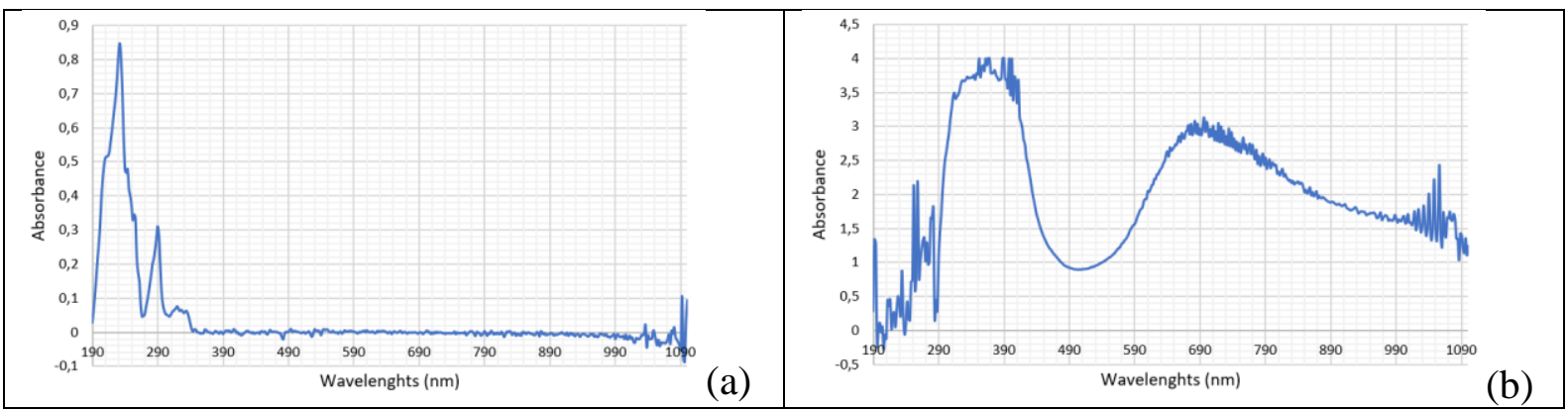


Figure 5. The UV/Visible spectra of $9 H$-carbazole solution (a) and of the polymer film obtained by oxidation of $9 H$-carbazole (b).

\subsection{Electrochemical oxidation of 3-substituted 9H-carbazoles}

The electrochemical oxidation of three 3 -substituted $9 H$-carbazole is carried out by cyclic voltammetry at a Pt electrode (Fig. 6a-6c-6e). For all 3-substituted $9 H$-carbazole monomers, an anodic peak is visible at $+1.1-1.2 \mathrm{~V} / \mathrm{SCE}$ during the first scan. During subsequent scans, the intensity of the oxidation peak increases steadily, and the peak potential shifts slowly to higher values. The gradual increase in oxidation peak intensity with repeated scans evidences the formation of adherent green films of conductive substituted polycarbazoles. Moreover, it can be noted that the intensity of the oxidation peak is maximum in the case of polyCz since we obtain a value of $152 \mu \mathrm{A}$ against respective values of 120,96 and $74 \mu \mathrm{A}$ for polyCz $\mathrm{H}_{1}$, polyCzH $\mathrm{C}_{2}$, and polyCzH 3 , respectively. This means that the addition of styryl and naphthalenyl vinyl groups on carbazole monomers does not lead to an increase in the current intensity and conductive behavior of the resulting polymer films. However, the substituted polycarbazole films are electroactive as shown by the post-polymerization voltammetries which exhibit an oxidation peak and a reduction peak. In particular, the (E)-3-styryl-9H-carbazole monomers leads to a polymer film with a high electroactivity since the oxidation and reduction peaks of the polyCzH $\mathrm{C}_{3}$ films are more pronounced and intense than those of polyCzH $\mathrm{CH}_{1}$ and polyCzH containing naphthalenyl groups (Fig. 6b-6d-6f). As with the polyCz films, the intensity of the redox peaks decreases with repeated scans indicating that the doping/dedoping of the films becomes increasingly difficult. It is also noteworthy that all substituted polycarbazole films are electrochromic as they change from green during the oxidation phase to colorless during the reduction phase in the potential range chosen for the cyclic voltammetries. 


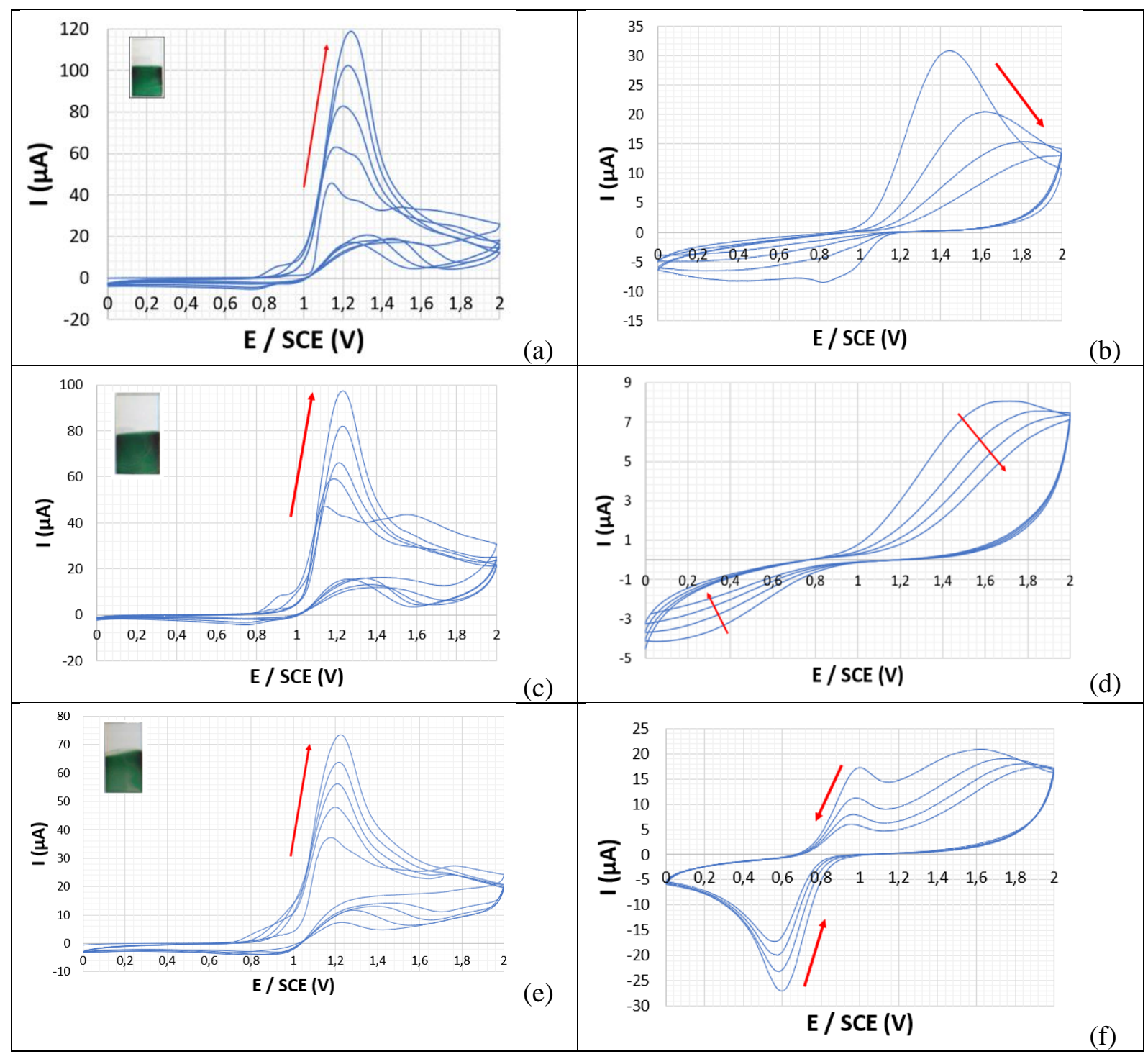

Figure 6. Electrochemical oxidation of carbazole derivatives $(0.01 \mathrm{M})$ in acetonitrile $+0.1 \mathrm{M}$ $\mathrm{LiClO}_{4}$ : (a) $\mathrm{CzH}_{1}$, (b) $\mathrm{CzH}_{2}$, (c) $\mathrm{CzH}_{3}$. Post-polymerization cyclic voltammetry of the resulting films in acetonitrile $+0.1 \mathrm{M} \mathrm{LiClO}_{4}$ : (d) $\mathrm{CzH}_{1}$, (e) $\mathrm{CzH}_{2}$, (f) $\mathrm{CzH}_{3}$.

The morphology of the electrodeposited films obtained from 3-substituted $9 \mathrm{H}$-carbazoles is similar regardless of the substituent and consists in globules randomly distributed on the substrate with the presence of aggregates in some places and the presence of cracks, however much less marked than for polyCz film (Fig. 4). All the polymers obtained from carbazoles substituted in position 3 show a close average thickness (from 1.1 to $1.6 \mu \mathrm{m}$ ) and a low roughness (between 0.1 and $0.2 \mu \mathrm{m}$ ), but also close wavelengths as shown by spectrophotometry which is consistent with the green coloration of the three deposits. 
Therefore, it appears that the presence of a substituent in position 3 does not prevent the electropolymerization of the non-functionalized monomers at the nitrogen atom. This confirms the results obtained in our previous work which evidenced that carbazoles functionalized by an ethyl or phenyl group at the 3-position can be electropolymerized. In addition, the anodic oxidation of 3-substituted $9 H$-carbazole leads to conducting, electrochromic, thick and smooth films which also present less cracks that unsubstituted polycarbazole.

\subsection{Electrochemical oxidation of 3-substituted 9-methyl-9H-carbazoles}

The carbazole derivatives having the same substituents in 3-position as in the previous section but including a methyl group in the 9-position were also studied. In this way, the impact of adding a methyl group instead of a hydrogen in 9-position and of adding substituents in 3position can be determined by comparing with 9-methyl- $9 \mathrm{H}$-carbazole. The cyclic voltammetries of the three 3 -substituted 9-methyl- $9 H$-carbazole are very similar since they all show an oxidation peak between +1.0 and $+1.1 \mathrm{~V} / \mathrm{SCE}$ during the first potential scan, corresponding to the oxidation of monomers into radical cations (Fig. 7a-7c-7e). The intensity of the oxidation potential peak gradually decreases during the following cycles, and the potential of the oxidation peak significantly shifts toward anodic potentials which means that the anodic oxidation becomes increasingly difficult. In addition, the intensity of the oxidation peak is comparable for the unsubstituted 9-methyl-9H-carbazole $(46 \mu \mathrm{A})$ than for the substituted $\mathrm{CzMe}_{1}(44 \mu \mathrm{A})$ and $\mathrm{CzMe}_{3}(50 \mu \mathrm{A})$ carbazoles, but higher than for the $\mathrm{CzMe}_{2}(20$ $\mu \mathrm{A})$ carbazole derivative. Moreover, these polycarbazole derivatives are almost not electroactive since there is no significative reduction peak and the oxidation peaks gradually decreases (Fig. 7b-7d-7f). Besides, while an adherent green polymer film appears on the Pt surface at the end of the chronodeposition, no electrochromism is observed for the 3-substituted 9-methyl-9H-carbazoles in contrast to what was previously observed with the 3 -substituted $9 H$ - 
carbazoles. The maximum wavelength measured for polyCzMe $\mathrm{C}_{1}, \mathrm{polyCzMe}_{2}$ and polyCzMe 3 is quite similar $(640-650 \mathrm{~nm})$ but higher than that of unsubstituted polyCzMe $(550 \mathrm{~nm})$ and lower than the ones of polyCzH $\mathrm{C}_{1}$, polyCzH $\mathrm{CH}_{2}$ and polyCzH, indicating the impact of the substituents at the 3- and 9-positions on the optical properties of the polymer films (Table 1). Furthermore, the morphology of the 3-subsituted 9-methyl-9H-carbazoles differs from one to the other with the presence of more or less globules and more or less pronounced cracks (Fig. 8). This morphology is also very different from the one of polyCzMe which was a feather dustlike morphology. Finally, the thickness of the polyCzMe $\mathrm{Cilm}_{3}(2.8 \mu \mathrm{m})$ was higher than that of the polyCzMe $e_{1}$ and polyCzMe films $(1.6 \mu \mathrm{m})$ while the roughness of all polymer films was between 0.3 and $0.4 \mu \mathrm{m}$ (Table 1$)$.

Therefore, it appears that the simultaneous presence of a substituent in 3-position and a methyl group in 9-position does not prevent the electropolymerization of the carbazole derivatives. However, the obtained polymer films are no longer electrochromic and electroactive, which reduces their ability to be used for applications requiring such optical and electrical properties.

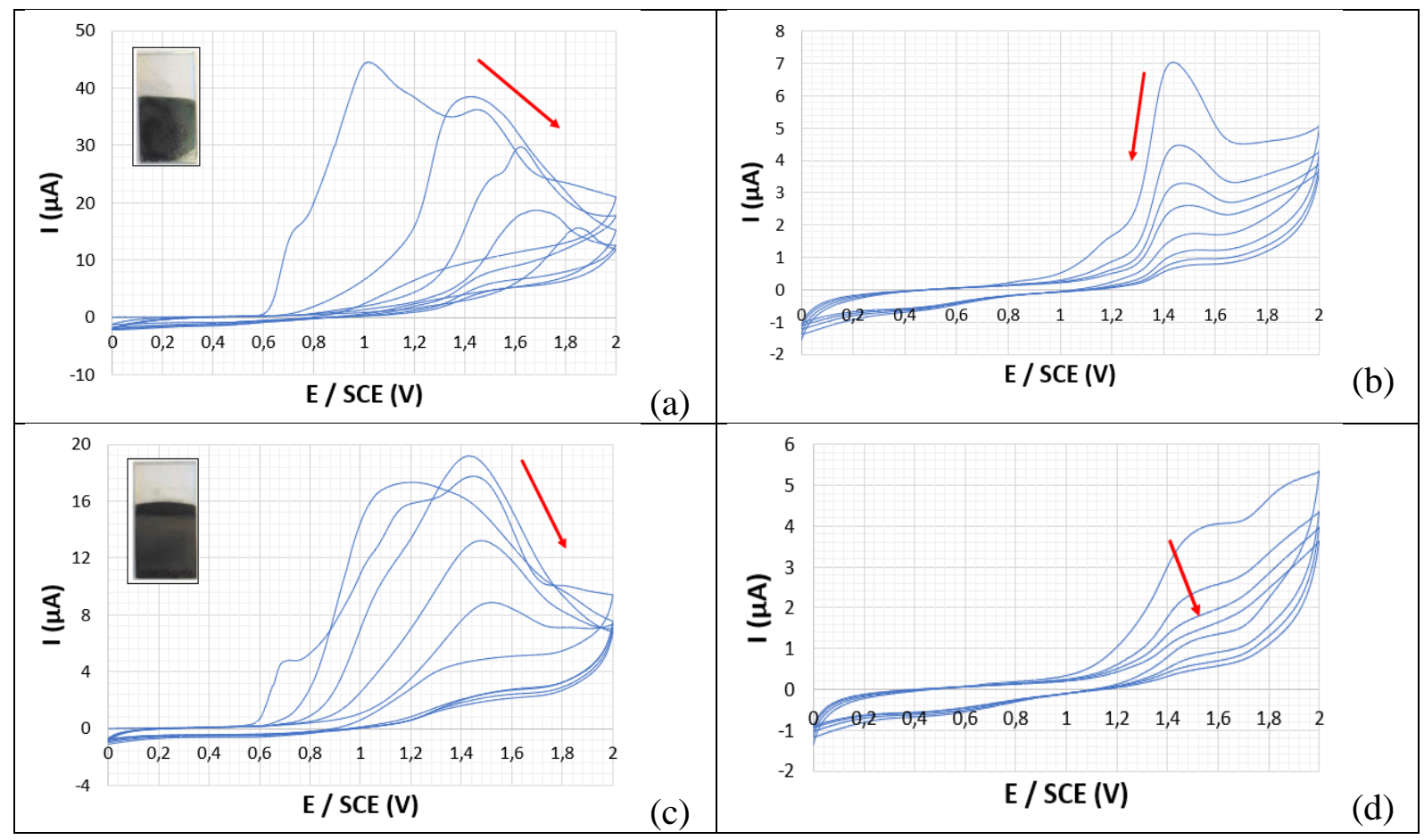




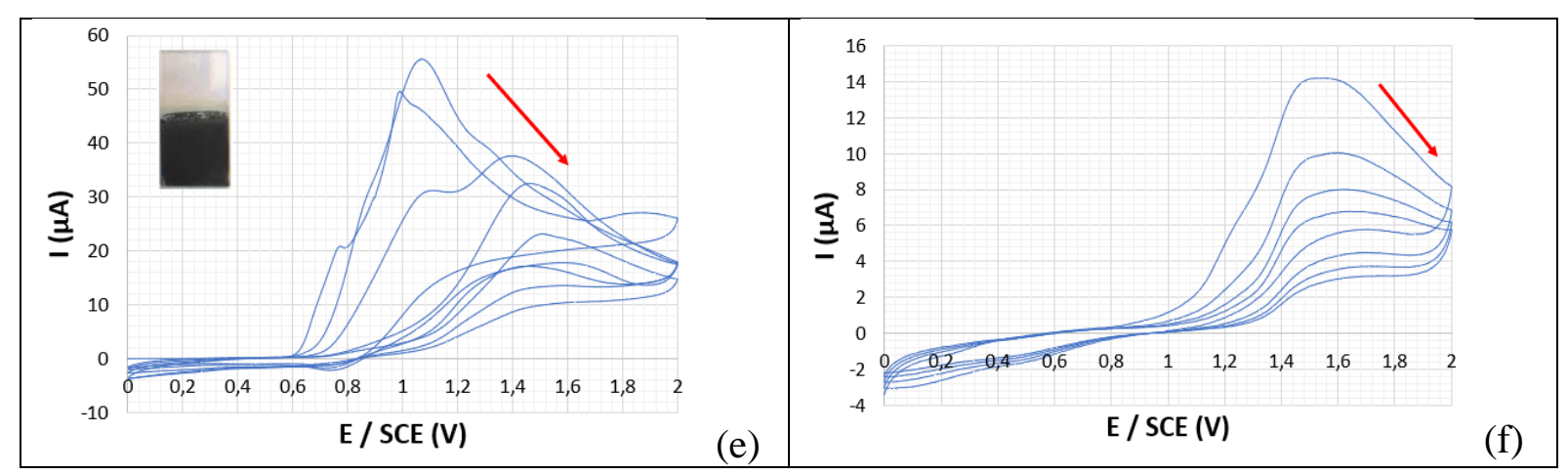

Figure 7. Electrochemical oxidation of carbazole derivatives $(0.01 \mathrm{M})$ in acetonitrile $+0.1 \mathrm{M}$

$\mathrm{LiClO}_{4}$ : (a) $\mathrm{CzMe}_{1}$, (b) $\mathrm{CzMe}_{2}$, (c) $\mathrm{CzMe}_{3}$. Post-polymerization cyclic voltammetry of the resulting films in acetonitrile $+0.1 \mathrm{M} \mathrm{LiClO}_{4}$ : (d) $\mathrm{CzMe}_{1}$, (e) $\mathrm{CzMe}_{2}$, (f) $\mathrm{CzMe}_{3}$.

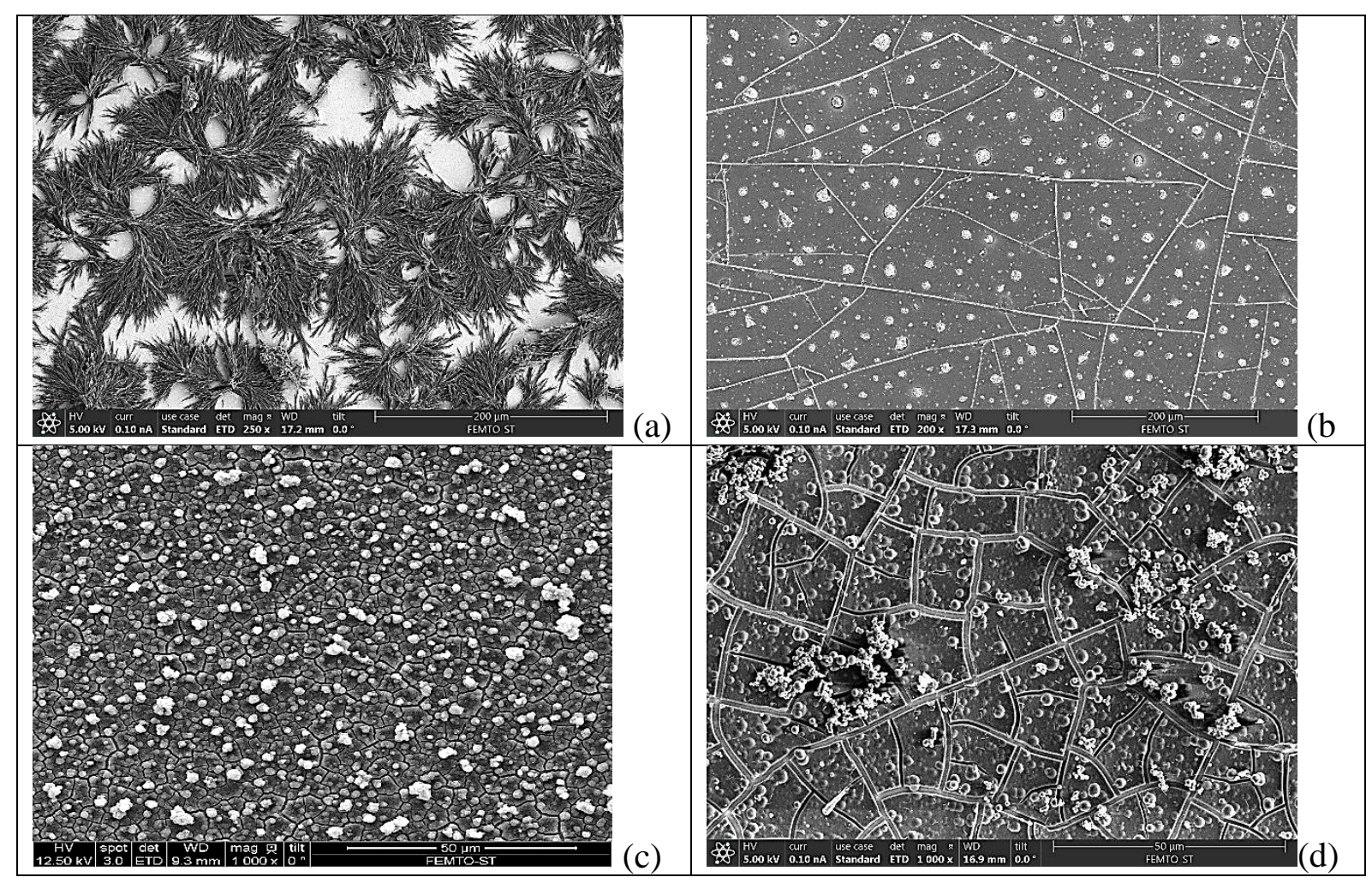

Figure 8. SEM images of the films obtained by oxidation of: $\mathrm{CzMe}$ (a), $\mathrm{CzMe}_{1}$ (b), $\mathrm{CzMe}_{2}$ (c) and $\mathrm{CzMe}_{3}(\mathrm{~d})$.

\subsection{Electrochemical oxidation of 3-substituted 9-benzyl-9H-carbazoles}

Carbazole derivatives with the same substituents in 3-position as in the previous section but incorporating a benzyl group in the 9-position were then investigated. A peak corresponding to 
the oxidation of (E)-3-styryl-9H-carbazole monomers $\left(\mathrm{CzBn}_{3}\right)$ was visible at $+1.1 \mathrm{~V} / \mathrm{SCE}$ during the first scan of cyclic voltammetry (Fig. 9e) while this oxidation peak appears at +1.4 V/SCE for (E)-9-methyl-3-(2-(naphthalen-1-yl)vinyl)-9H-carbazole ( $\left.\mathrm{CzBn}_{1}\right)$ and (E)-9methyl-3-(2-(naphthalen-2-yl)vinyl)-9H-carbazole $\left(\mathrm{CzBn}_{2}\right)$ (Fig. 9a-9c). After the first scan, the intensity of the oxidation potential peak gradually decreases for all three carbazoles, and the oxidation peak potential of $\mathrm{CzBn}_{1}$ and $\mathrm{CzBn}_{3}$ shifts significantly toward anodic potentials. At the end of the cyclic voltammetry or chronoamperometric experiment, an adherent green polymer film of polyCzBn 1 or polyCzBn 3 can be observed on the surface of the working electrode. On the contrary, the $\mathrm{CzBn}_{2}$ monomers are oxidized, as evidenced by the presence of an oxidation peak, leading to the formation of polymer on the working electrode but the polymer does not adhere well to the substrate, and it mainly falls into the solution (which turns green) although a very thin film remains attached to the substrate. As a result, the intensity of the oxidation peak is very low for $\mathrm{CzBn}_{2}(9 \mu \mathrm{A})$ and this very thin film of polyCzBn 2 is not electroactive (Fig. 9d). The intensity of the oxidation peak of $\mathrm{CzBn}_{1}(23 \mu \mathrm{A})$ and $\mathrm{CzBn}_{3}(40$ $\mu \mathrm{A})$ is higher but the electroactivity is still limited because there is almost no reduction peak and the oxidation peak has a low intensity of 3-5 $\mu \mathrm{A}$ (Fig. 9b-9f). Besides, no electrochromism is observed for all 3-substituted 9-benzyl-9H-carbazoles in contrast to what was observed with 3-substituted $9 H$-carbazoles. The maximum wavelength measured for polyCzBn 1 and polyCzBn 3 are similar $(650 \mathrm{~nm})$ and very close to that of the 3-substituted 3-methyl-9Hcarbazoles (Table 1). The morphology of the polyCzBn${ }_{1}$ and polyCzBn 3 films is quite similar (Fig. 10b-10d). It shows globules which are mostly clustered to form large aggregates, the presence of cracks can also be noticed. The thickness and roughness of these two films are also not very different since the polyCzBn${ }_{1}$ film has a thickness of $1.6 \mu \mathrm{m}$ and a roughness of 0.5 $\mu \mathrm{m}$ while the polyCzBn 3 film has a thickness of $2.2 \mu \mathrm{m}$ and a roughness of $0.6 \mu \mathrm{m}$ (Table 1 ). 
The image of the polyCzBn 2 film was given but is not really significant because of its very low thickness.

It thus appears that the simultaneous presence of a substituent in position 3 and a benzyl group in position 9 does not prevent the electro-oxidation of carbazole derivatives. However, the resulting polymer films are no longer electrochromic and electroactive. These films, as well as those obtained with methyl groups in position 3, therefore appear less interesting than the films obtained by electro-oxidation of monomers substituted in position 3 but not substituted in position 9.

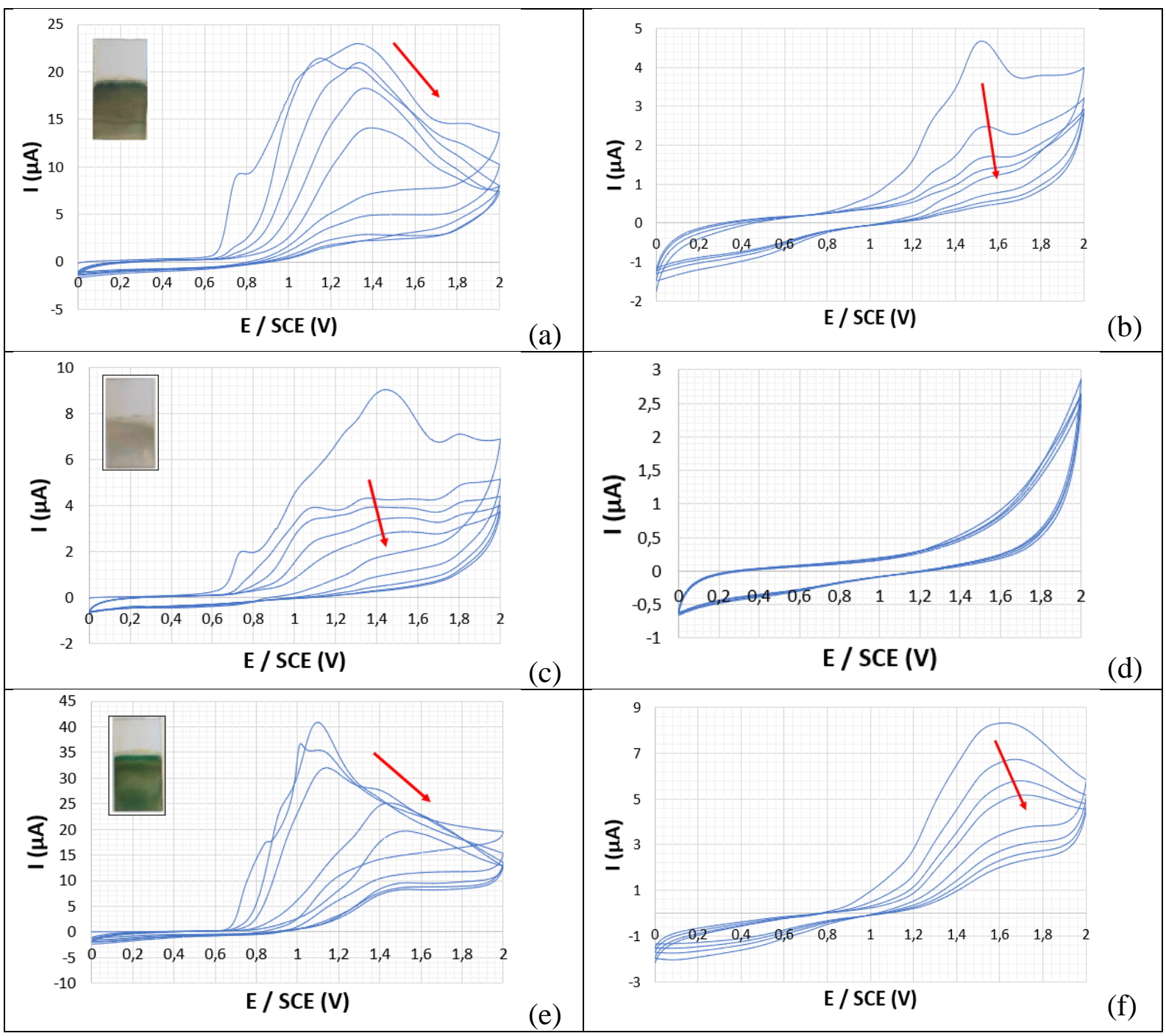


Figure 9. Electrochemical oxidation of carbazole derivatives $(0.01 \mathrm{M})$ in acetonitrile $+0.1 \mathrm{M}$ $\mathrm{LiClO}_{4}$ : (a) $\mathrm{CzBn}_{1}$, (b) $\mathrm{CzBn}_{2}$, (c) $\mathrm{CzBn}_{3}$. Post-polymerization cyclic voltammetry of the resulting films in acetonitrile + $0.1 \mathrm{M} \mathrm{LiClO}_{4}$ : (d) $\mathrm{CzBn}_{1}$, (e) $\mathrm{CzBn}_{2}$, (f) $\mathrm{CzBn}_{3}$.

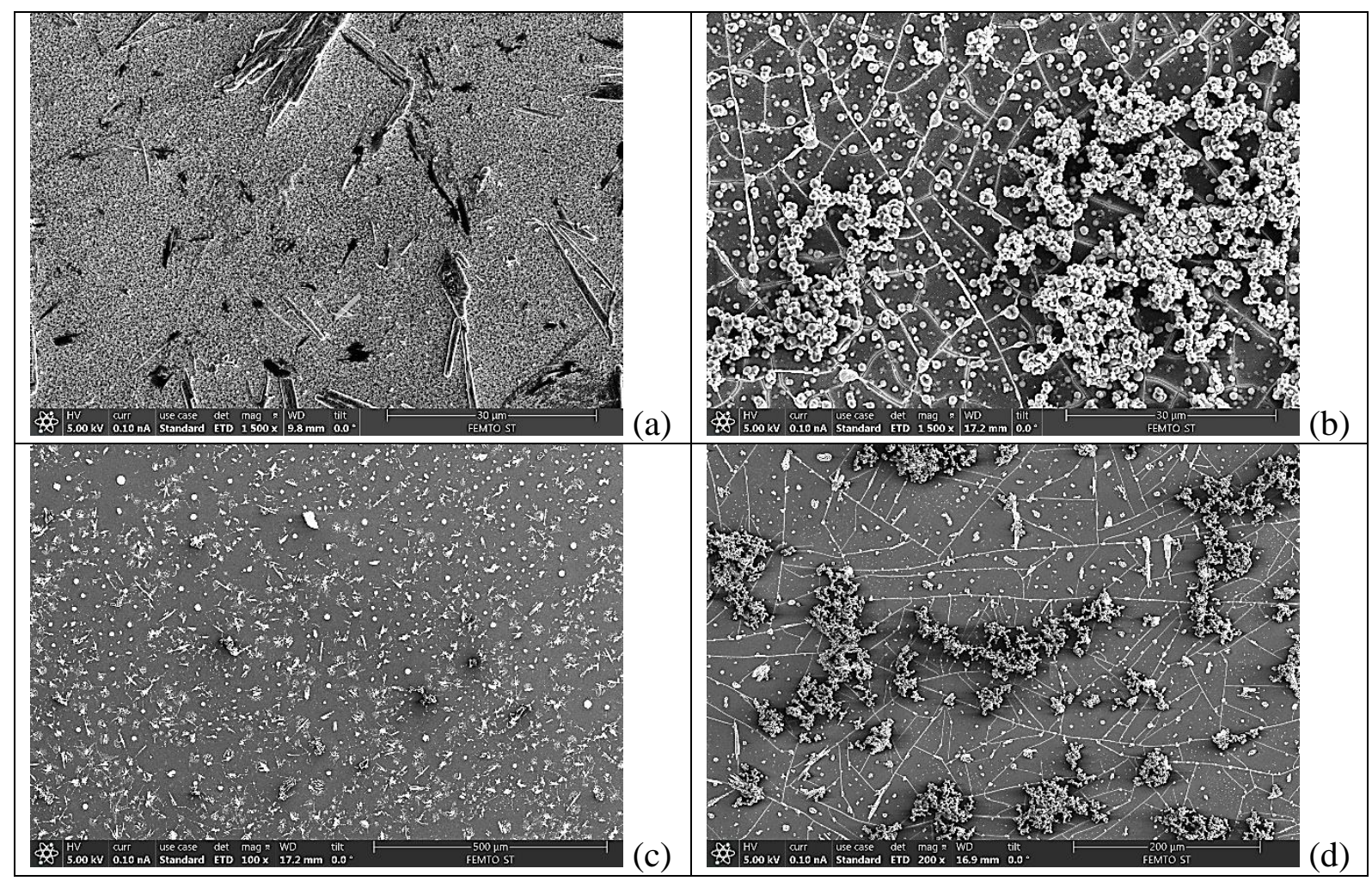

Figure 10. SEM images of the films obtained by oxidation of: $\mathrm{CzBn}$ (a), $\mathrm{CzBn}_{1}$ (b), $\mathrm{CzBn}_{2}$ (c) and $\mathrm{CzBn}_{3}(\mathrm{~d})$.

\subsection{Comparison of physico-chemical properties and reaction mechanism}

\subsubsection{Comparison of physico-chemical properties}

In order to better compare the properties of the polymer films obtained by electrochemical oxidation using the different carbazole derivatives, the results obtained previously are gathered in Table 2. It appears clearly that the polymer films obtained from derivatives not substituted in position 9 are the most interesting because the films obtained are thick, adherent, homogeneous, electroactive, and electrochromic. These last two aspects suggest that they can be used for applications in the field of optics thanks to their electrochromism or in the field of 
resistive sensors thanks to their conductivity and electroactivity. It also appears that the addition of naphthalenyl vinyl and styryl groups in position 3 does not prevent the electropolymerization of these monomers, and that it does not deprive the films of their electroactive and electrochromic properties.

When monomers with the same groups in the 3-position but methyl or benzyl groups in the 9-position are substituted for hydrogen atoms, the electrochemical oxidation of the monomers continues to occur as does the polymerization. However, the films obtained generally present a much lower electroactivity and they are no longer electrochromic, which limits the possibilities of use. In some cases $\left(\mathrm{CzBn}\right.$ and $\left.\mathrm{CzBn}_{2}\right)$, it is even observed that the polymer has great difficulty in adhering to the substrate. Overall, it can be noticed that polymer films obtained from monomers with benzyl groups in 9-position have less interesting properties than those with methyl groups in position 9 which possess better electroactivity, more homogeneous morphology with less aggregates, and lower roughness.

\begin{tabular}{|c|c|c|c|c|c|c|c|c|}
\hline & \multirow[b]{2}{*}{$\mathrm{i}_{\mathrm{p}}(\mu \mathrm{A})^{*}$} & \multirow[b]{2}{*}{$\mathrm{T}(\mu \mathrm{m})$} & \multirow[b]{2}{*}{$\mathrm{R}(\mu \mathrm{m})$} & \multicolumn{2}{|c|}{ AWM (nm) } & \multirow{2}{*}{$\begin{array}{l}\text { Electro- } \\
\text { activity }\end{array}$} & \multirow[b]{2}{*}{ Film } & \multirow{2}{*}{$\begin{array}{c}\text { Electrochr } \\
\text { omism }\end{array}$} \\
\hline & & & & $\begin{array}{l}\text { Monomer } \\
\text { solution }\end{array}$ & $\begin{array}{l}\text { Polymer } \\
\text { film }\end{array}$ & & & \\
\hline $\mathrm{Cz}$ & 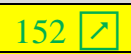 & 2.0 & 0.1 & 230,290 & 340,690 & High & Thick (green) & Yes \\
\hline $\mathrm{CzH}_{1}$ & 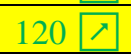 & 1.3 & 0.2 & 220,290 & 310,790 & High & Thick (green) & Yes \\
\hline $\mathrm{CzH}_{2}$ & 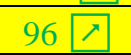 & 1.6 & 0.2 & 220,290 & 310,780 & Medium & Thick (green) & Yes \\
\hline $\mathrm{CzH}_{3}$ & 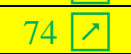 & 1.1 & 0.1 & 230,290 & 310,770 & High & Thick (green) & Yes \\
\hline $\mathrm{CzMe}$ & $45 \square$ & 6.0 & 3.0 & $260,290,340$ & 305,550 & Low & Thick (green) & No \\
\hline $\mathrm{CzMe}_{1}$ & $44 \square$ & 1.6 & 0.3 & $210,290,340$ & 310,650 & Low & Thick (green) & No \\
\hline $\mathrm{CzMe}_{2}$ & $20 \square$ & 1.6 & 0.4 & $210,290,340$ & 310,640 & Low & Thick (green) & No \\
\hline $\mathrm{CzMe}_{3}$ & $50 \searrow$ & 2.8 & 0.3 & $240,300,340$ & 320,640 & Medium & Thick (green) & No \\
\hline $\mathrm{CzBn}$ & $45 \searrow$ & $<0.5$ & --- & $260,290,340$ & --- & Low & Very Thin & $\mathrm{No}$ \\
\hline $\mathrm{CzBn}_{1}$ & $23 \searrow$ & 1.6 & 0.5 & $220,290,320$ & 305,650 & Low & Thick (green) & No \\
\hline $\mathrm{CzBn}_{2}$ & $9 \searrow$ & $<0.5$ & --- & $220,290,330$ & --- & Very low & Very thin & $\mathrm{No}$ \\
\hline $\mathrm{CzBn}_{3}$ & 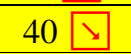 & 2.2 & 0.6 & $230,290,320$ & 310,660 & Low & Thick (green) & No \\
\hline
\end{tabular}

* Intensity of the monomer oxidation peak ( $1^{\text {st }}$ scan) and evolution of the intensity of the monomer oxidation peak with repeated scans, T: thickness of the films, R: roughness of the films, AWM: values of the absorption wavelength peak maxima observed in the UV/Visible spectra of the monomer solutions and electrodeposited films.

Table 1. Sum-up of the properties of the films obtained by oxidation of carbazole monomers (in green: beneficial properties, in red: adverse properties, in black: neutral properties). 


\subsubsection{Reaction mechanism}

The radical polymerization of carbazole derivatives starts with the oxidation of the monomer at the electrode which leads to the formation of a radical cation on the nitrogen atom (Fig. 11). Then, the radical delocalizes to the $\mathrm{C}_{6}$ position due to the conjugated bonds and a $\mathrm{C}_{6}-\mathrm{C}_{6}{ }^{\prime}$ coupling occurs between two monomers in the form of radical cation because the radical cations formed are not stable. $\mathrm{C}_{9}-\mathrm{C}_{9}{ }^{\prime}$ coupling is not possible when the $\mathrm{C}_{9}$ position is already occupied. Moreover, coupling at the $\mathrm{C}_{1}$ or $\mathrm{C}_{8}$ position is possible but steric hindrance means that the amount of dimers formed is very low. There is then a deprotonation of $\mathrm{C}_{6}$ and $\mathrm{C}_{6}$ ' to restore the aromaticity of the benzene rings, followed by a new oxidation with the loss of one electron on the nitrogen atom, forming a radical cation (the polymerization takes place at 6 and 6 ' positions because they are the easiest positions to oxidize in the carbazole structure [52]). This time, the radical is no longer delocalized in $\mathrm{C}_{6}$ because the position is substituted, but on the aromatic rings of the substituent in $C_{3}\left(R_{2}\right.$ group) because there is conjugation between the substituted group and the carbazole core. There is then the possibility of a coupling between the $\mathrm{C}_{6}$ of a radical monomer and this radical dimer. If the propagation is regular, the termination may be a recombination between the $\mathrm{R}_{2}$ of one oligomer and the $\mathrm{R}_{2}$ of another one. 


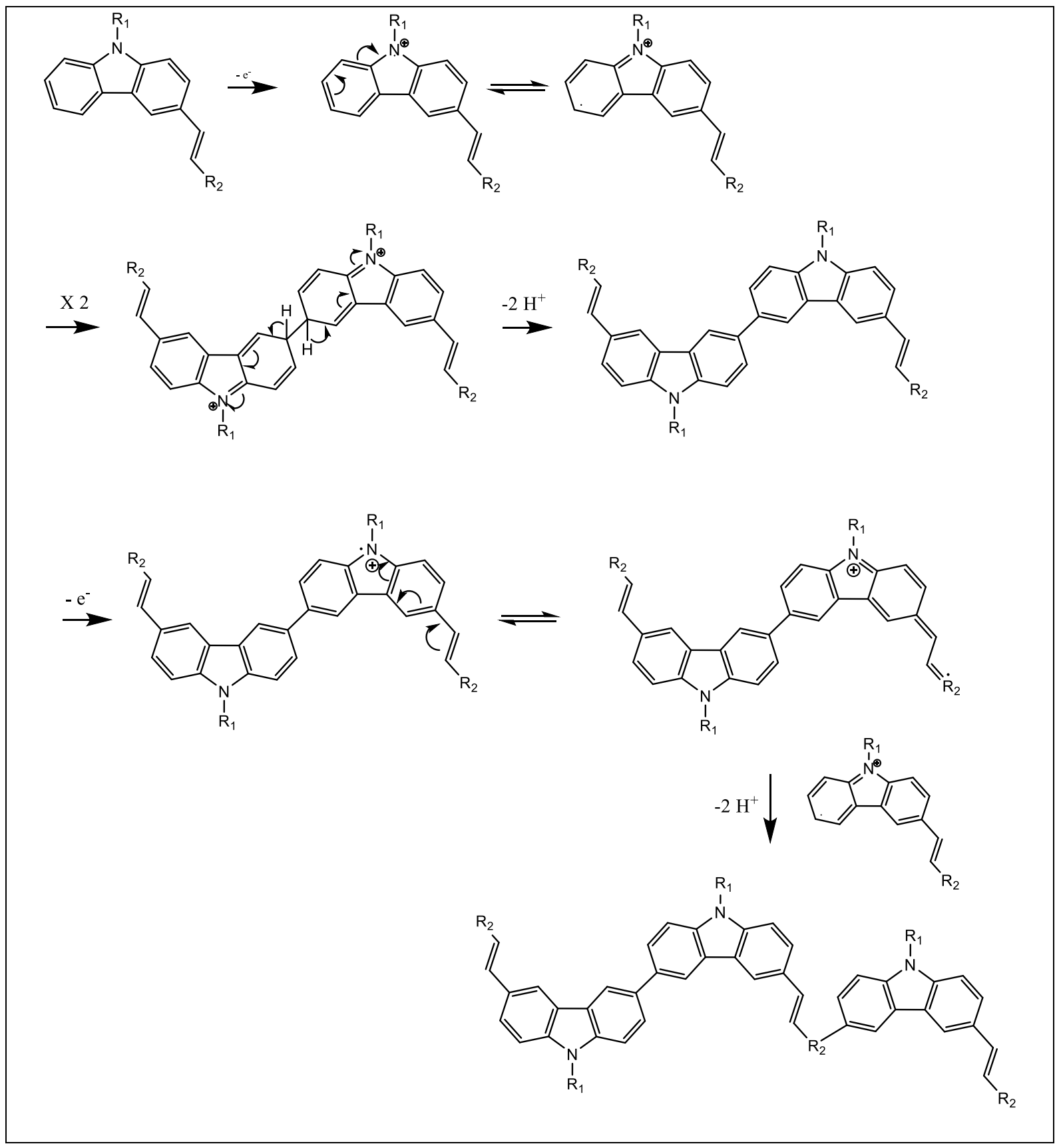

Figure 11. Possible reaction mechanism for the electropolymerization of carbazole derivatives.

\section{Conclusion}

A series of substituted carbazole monomers was synthesized by grafting methyl and benzyl groups at 9-position or/and highly conjugated groups at 3-position. After dissolving the substituted monomers in acetonitrile solutions, electrochemical polymerization of the monomers was successfully performed for all carbazole derivatives. Strong differences were 
observed depending on the nature of the substituent used. Indeed, the most interesting films were obtained by electro-oxidation of carbazoles substituted at the 3-position but not substituted at the 9-position since these films were electroactive and electrochromic, adherent, and homogeneous. The presence of a methyl group at the 9-position does not prevent electropolymerization from taking place and leads to the formation of green adherent polymer films even though these films are not electrochromic and less electroactive. On the contrary, the presence of a benzyl group on the 9-position strongly decreases the adhesion of the polymer films and in some cases the film fails to adhere to the substrate during electro-oxidation. It thus appears that the nature of the substituent grafted at 9-position has an important impact on the physicochemical properties of the electrodeposited films. Different substituents were used to functionalize the carbazole monomers at the 3-position but the impact of this functionalization on the properties of the film was much weaker which can be qualified by the fact that the substituents were not very different from each other. In the future, we plan to use the electrochromism and electroactivity of the polymers obtained from 3-substituted- $9 \mathrm{H}$ carbazoles to develop chemical sensors, and to try to improve the adhesion of the polymer film functionalized with benzyl groups at the 9-position using an adhesion promoter.

\section{References}

[1] H. Shirakawa, E.J. Louis, A.G. MacDiarmid, C.K. Chiang, A.J. Heeger, Synthesis of electrically conducting organic polymers: halogen derivatives of polyacetylene, $(\mathrm{CH})_{\mathrm{x}}, \mathrm{J}$. Chem. Soc. Chem. Commun. 16 (1977) 578-580.

[2] Y.B. Shim, S.M. Park, Electrochemistry of conductive polymers VII, Autocatalytic rate constant for polyaniline growth, Synth. Met. 29 (1989) E169-E174.

[3] A.F. Diaz, K.K. Kanazawa, Electrochemical polymerization of pyrrole. J. Chem. Soc. Chem. Commun. 14 (1979) 635-636. 
[4] G. Tourillon, F. Garnier, New electrochemically generated organic conducting polymers. J. Electroanal. Chem. 135 (1982) 173-178.

[5] T.H. Le, Y. Kim, H. Yoon, Electrical and Electrochemical Properties of Conducting Polymers, Polymers 9 (2017) 150.

[6] K. Namsheer, C.S. Rout, Conducting polymers: a comprehensive review on recent advances in synthesis, properties and applications, RSC Adv. 11 (2021) 5659-5697.

[7] P. Xu, A. Singh, D.L. Kaplan, Enzymatic Catalysis in the Synthesis of Polyanilines and Derivatives of Polyanilines. In: Kobayashi S., Ritter H., Kaplan D. (eds) Enzyme-Catalyzed Synthesis of Polymers. Advances in Polymer Science, vol. 194. Springer, Berlin, Heidelberg. [8] A.T. Lawal, G.G. Wallace, Vapour phase polymerisation of conducting and non-conducting polymers: A review, Talanta, 119(2014) 133-143.

[9] H.R. Heydarnezhad, B. Pourabbas, M. Tayefi, Conducting Electroactive Polymers via Photopolymerization: A Review on Synthesis and Applications, Polym. Plast. Techn. Eng. 57 (2018) 1093-1109.

[10] Y. Han, L. Dai, Conducting Polymers for Flexible Supercapacitors, Macromol. Chem. Phys. 220 (2019) 1800355.

[11] S. Suriyakumar, P. Bhardwaj, A.N. Grace, A.M. Stephan, Role of Polymers in Enhancing the Performance of Electrochemical Supercapacitors: A Review, Batter. Supercaps. 4 (2021) $571-584$

[12] X. Jia, Y. Ge, L. Shao, C. Wang, G.G. Wallace, Tunable Conducting Polymers: Toward Sustainable and Versatile Batteries, ACS Sustain. Chem. And Eng. 7 (2019) 14321-14340.

[13] X. Cao, J. Liu, L. Zhu, L. Xie, Polymer Electrode Materials for High-Performance Lithium/Sodium-Ion Batteries: A Review, Energy Techn.7 (2019) 1800759. 
[14] S.A. Umoren, M.M. Solomon, Protective polymeric films for industrial substrates: A critical review on past and recent applications with conducting polymers and polymer composites/nanocomposites, Progr. Mater. Sci. 104 (2019) 380-450.

[15] P.P. Deshpande, N.G. Jadhav, V.J. Gelling, D. Sazou, Conducting polymers for corrosion protection: a review, J. Coat. Technol. Res. 11 (2014) 473-494.

[16] Y.C. Wong, B.C. Ang, A.S.M.A. Haseeb, A.A. Baharuddin, Y.H. Wong, Conducting Polymers as Chemiresistive Gas Sensing Materials: A Review, J. Electrochem. Soc. 167 (2020) 037503.

[17] I. Fratoddi, I. Venditti, C. Cametti, M.V. Russo, Chemiresistive polyaniline-based gas sensors: A mini review, Sens. Actuators B, 220 (2015) 534-548.

[18] F.G. Zamani, H. Moulahoum, M. Ak, D.O. Demirkol, S. Timur, Current trends in the development of conducting polymers-based biosensors, TrAC 118 (2019) 264-276.

[19] B. Lakard, Electrochemical Biosensors Based on Conducting Polymers: A Review, Appl. Sci. 10 (2020) 6614.

[20] A.R. Murad, A. Iraqi, S.B. Aziz, S.N. Abdullah, M.A. Brza, Conducting Polymers for Optoelectronic Devices and Organic Solar Cells: A Review, Polymers 12 (2020) 2627.

[21] S. Ahn, S.H. Jeong, T.H. Han, T.W. Lee, Conducting Polymers as Anode Buffer Materials in Organic and Perovskite Optoelectronics, Adv Optics Mater. 5 (2017) 1600512.

[22] Kenry, B. Liu, Recent Advances in Biodegradable Conducting Polymers and Their Biomedical Applications, Biomacromolecules 19 (2018) 1783-1803.

[23] Z. Aqrawe, J. Montgomery, J. Travas-Sejdic, D. Svirskis, Conducting polymers for neuronal microelectrode array recording and stimulation, Sens. Actuators B 257 (2018) 753765.

[24] K. Karon, M. Lapkowski, Carbazole electrochemistry: a short review. J. Solid. State Electrochem. 19 (2015) 2601-2610. 
[25] P.L. Boudreault, S. Beaupré, M. Leclerc, Polycarbazoles for plastic electronics, Polym. Chem. 1 (2010) 127-136.

[26] J.F. Morin, M. Leclerc, D. Ades, A. Siove, Polycarbazoles: 25 years of progress, Macromol. Rapid Commun. 26 (2005) 761-778.

[27] V. Nayana, B. Kandasubramanian, Polycarbazole and its derivatives: progress, synthesis, and applications, J. Polym. Res. 27 (2020) 285.

[28] H.P. Liang, Q. Chen, B.H. Han, Cationic Polycarbazole Networks as Visible-Light Heterogeneous Photocatalysts for Oxidative Organic Transformations, ACS Catal. 8 (2018) $5313-5322$.

[29] S. Grigalevicius, B. Zhang, Z. Xie, M. Forster, U. Scherf, Polycarbazole-based networks made by photo-crosslinking for hole transporting layers of OLED devices, Org. Electron. 12 (2011) 2253-2257.

[30] N.A. Rice, W.J. Bodnaryk, B. Mirka, O.A. Melville, A. Adronov, B.H. Lessard, Polycarbazole-Sorted Semiconducting Single-Walled Carbon Nanotubes for Incorporation into Organic Thin Film Transistors, Adv. Electron. Mater. 5 (2019) 1800539.

[31] S. Alem, N. Graddage, J. Lu, T. Kololuoma, R. Movileanu, Y. Tao, Flexographic printing of polycarbazole-based inverted solar cells, Org. Electron. 52 (2018) 146-152.

[32] Y. Xie, X. Wang, Q. Chen, S. Liu, X. Wang, Y. Yun, Y. Liu, C. Chen, J. Wang, Y. Cao, F. Wang, T. Qin, W. Huang, Dopant-Free Hole-Transporting Polycarbazoles with Tailored Backbones for Efficient Inverted Perovskite Solar Cells, Macromolecules 52 (2019) 47574764.

[33] N. Joshi, V. Saxena, A. Singh, S.P. Koiry, A.K. Debnath, M.M. Chehimi, D.K. Aswal, S.K. Gupta, Flexible $\mathrm{H}_{2} \mathrm{~S}$ sensor based on gold modified polycarbazole films, Sens. Actuators B, 200 (2014) 227-234. 
[34] T. Soganci, Y. Baygu, N. Kabay, Y. Gök, M. Ak, Comparative investigation of peripheral and nonperipheral zinc phthalocyanine-based polycarbazoles in terms of optical, electrical, and sensing properties, ACS Appl. Mater. Interfaces 10 (2018) 21654-21665.

[35] S. Zukauskas, A. Ramanavicius, G. Bagdziunas, J. Electrochem. Soc. 166 (2019) B316.

[36] G. Bagdziunas, D. Palinauskas, Poly(9H-carbazole) as a Organic Semiconductor for Enzymatic and Non-Enzymatic Glucose Sensors, Biosensors 10 (2020) 104.

[37] G.E.K. Branch, J.F. Smith, A bivalent nitrogen derivative of carbazole. J Am Chem Soc 42 (1920) 2405-2413.

[38] W.H. Perkin, S.H. Tucker, The oxidation of carbazole. J. Chem. Soc. Trans. 119 (1921) 216-225.

[39] J.F. Ambrose, R.F. Nelson RF, Anodic oxidation pathways of carbazoles (I. Carbazole and N-substituted derivatives), J. Electrochem. Soc. 115 (1968) 1159-1163.

[40] J.F. Ambrose, L.L. Carpenter, R.F. Nelson, Electrochemical and Spectroscopic Properties of Cation Radicals: III. Reaction Pathways of Carbazolium Radical Ions, J. Electrochem. Soc. Electrochem. Sci. Techn. 122 (1975) 876-894.

[41] F. Bekkar, F. Bettahar, I. Moreno, R. Meghabar, M. Hamadouche, E. Hernaez, J.L. VilasVilela, L. Ruiz-Rubio, Polycarbazole and its derivatives: synthesis and applications. A review of last 10 years. Polymers 12 (2020) 2227.

[42] G. Mengoli, M.M. Musiani, B. Schreck, S. Zeccin, Electrochemical synthesis and properties of polycarbazole films in protic acid media, J. Electroanal. Chem. 1988, 246, 73-86. [43] S. Cattarin, G. Mengoli, M.M. Musiani, B. Schreck, Synthesis and properties of film electrodes from n-substituted carbazoles in acid medium, J. Electroanal. Chem. 246 (1988) 87100. 
[44] P. Marrec, C. Dano, N. Gueguen-Simonet, J. Simonet, The anodic oxidation and polymerization of carbazoles and dicarbazoles N-substituted by polyether chains, Synth. Met. 89 (1997) 171-179.

[45] E. Contal, C.M. Sougueh, S. Lakard, A. Et Taouil, C. Magnenet, B. Lakard, Investigation of Polycarbazoles Thin Films Prepared by Electrochemical Oxidation of Synthesized Carbazole Derivatives, Frontiers Mater. 6 (2019) 131.

[46] A. Et Taouil, E. Contal, S. Lakard, B. Lakard, Investigation of electrochemical oxidative coupling of 3 and 6 substituted carbazoles, J. Electroanal. Chem. 894 (2021) 115356.

[47] A. Al Mousawi, P. Garra, F. Dumur, T.T. Bui, F. Goubard, J. Toufaily, T. Hamieh, B. Graff, D. Gigmes, J.P. Fouassier, J. Lalevée, Novel Carbazole Skeleton-Based Photoinitiators for LED Polymerization and LED Projector 3D Printing, Molecules 22 (2017) 2143

[48] S. Sadki, P. Schottland, N. Brodie, G. Sabouraud, The mechanisms of pyrrole electropolymerization, Chem. Soc. Rev. 29 (2000) 283-293.

[49] I. Jureviciute, S. Bruckenstein, Electrochemical activity of chemically deposited polypyrrole films, J. Solid State Electrochem. 7 (2003) 554-560.

[50] D. Rodriquez, J.G. Kohl, P. Morel, K. Burrows, G. Favaro, S.E. Root, J. Ramirez, M.A. Alkhadra, C.W. Carpenter, Z. Fei, P. Boufflet, M. Heeney, D.J. Lipomi, Measurement of Cohesion and Adhesion of Semiconducting Polymers by Scratch Testing: Effect of Side-Chain Length and Degree of Polymerization, ACS Macro Lett. 7 (2018) 1003-1009.

[51] S. Lakard, E. Contal, K. Mougin, C. Magnenet, B. Lakard, Electrochemical preparation and physicochemical study of polymers obtained from carbazole and $\mathrm{N}$ ((methoxycarbonyl)methyl)carbazole, Synth. Met. 270 (2020) 116584.

[52] J.F. Morin, M. Leclerc, D. Adès, A. Siove, Polycarbazoles: 25 Years of Progress, Macromol. Rapid Commun. 26 (2005) 761-778. 
